\title{
CONSTITUCIÓN, DESARROLLO Y MEDIO AMBIENTE EN UN CONTEXTO DE CRISIS ${ }^{1}$
}

\author{
JORDI JARIA I MANZANO \\ Profesor agregado Serra Húnter de Derecho Constitucional y \\ Ambiental \\ Universitat Rovira i Virgili \\ jordi.jaria@urv.cat
}

Recibido: 05/07/2017 Aceptado: 03/09/2017

RESUMEN: El desarrollo sostenible ha devenido en los últimos decenios la matriz conceptual dominante a la hora de definir, en el ámbito de la política y el derecho, la reacción ante la modificación significativa de la base biofísica de la reproducción social, fenómeno que ha dado lugar a distintas narrativas críticas o de transición, como la del Antropoceno. El objeto del presente estudio es ver cómo la tensión entre desarrollo y preservación de la biosfera, que pretende resolver la idea de desarrollo sostenible, persiste, y cómo la prioridad del desarrollo se acaba proyectando sobre las políticas públicas y las soluciones legislativas en el contexto de la crisis económica iniciada en 2007. En particular, se va a analizar cómo ha respondido el Tribunal Constitucional español a los diferentes contenciosos que se han producido alrededor de la mencionada tensión, así como la singularidad de su configuración en el marco del Estado autonómico. Se concluirá con un análisis crítico de esta

\footnotetext{
${ }^{1}$ Este trabajo parte de la investigación realizada en el marco de la Red de Investigación ECOVER "Mercado y medioambiente. Propuestas jurídicas para una economía verde", reconocida por Resolución del Conselleiro de Cultura, Educación y Ordenación Universitaria de la Xunta de Galicia de 8 de octubre de 2014, por la que se conceden ayudas para la consolidación y estructuración de unidades de investigación competitivas del Sistema Universitario de Galicia, convocadas mediante la Orden de 14 de mayo de 2014 (DOG de 17 de octubre de 2014), período 2014-2015; investigador principal: Francisco Javier Sanz Larruga. Posteriormente, ha sido desarrollado dentro del proyecto de investigación "Constitución climática global: gobernanza y Derecho en un contexto complejo", financiado por el Ministerio de Economía y Competitividad para el trienio 2017-2019 (proyecto DER2016-80011-P; investigadores principales: Jordi Jaria i Manzano y Susana Borràs Pentinat).
} 
jurisprudencia constitucional, apuntando hacia patrones hermenéuticos distintos que darían lugar a un rol diferente del mantenido por el juez de la constitucionalidad.

RESUM: El desenvolupament sostenible ha esdevingut en les últimes dècades la matriu conceptual dominant a l'hora de definir, en l'àmbit de la política i el dret, la reacció davant de la modificació significativa de la base biofísica de la reproducció social, fenomen que ha donat lloc a diferents narratives crítiques o de transició, com la del Antropocè. L'objecte de l'estudi present és veure com la tensió entre desenvolupament i preservació de la biosfera, que pretén resoldre la idea de desenvolupament sostenible, persisteix, i com la prioritat del desenvolupament acaba projectant-se sobre les polítiques públiques i les solucions legislatives en el context de la crisi econòmica iniciada el 2007. En particular, s'analitzarà como ha respost el Tribunal Constitucional des d'aleshores als diferents contenciosos que s'han produït en relació amb la tensió esmentada, així com la singularitat de la seva configuració en el marc de l'Estat autonòmic. Es conclou amb una anàlisi crítica d'aquesta jurisprudència constitucional, apuntant cap a altres patrons hermenèutics que donarien Iloc a un rol diferent del mantingut per el jutge de la constitucionalitat.

ABSTRACT: Sustainable development has become in the last decades the hegemonic conceptual matrix to define the political and legal reaction against the backdrop of the transformation of the biophysical basis of social reproduction, in the context of different critic or transitional narratives, such as the Anthropocene. The aim of this paper is to analyze how the tension between development and environmental protection, which is intended to be solved through the idea of sustainable development, persists, and how the priority of development is projected over public policies and legislative solutions, in the context of the global crisis which began in 2007. Particularly, this study is aiming to summarize how the Spanish Constitutional Court has responded from then on to different cases showing the aforementioned tension. The particularities of the Spanish decentralized state regarding this issue should be analyzed as well. The paper concludes with a critical analysis of this case-law, 
showing how different hermeneutic patterns should give a different performance of the Constitutional Court.

PALABRAS CLAVE: Desarrollo sostenible - Crisis económica - Tribunal Constitucional — Estado autonómico.

PARAULES CLAU: Desenvolupament sostenible - Crisi econòmica — Tribunal Constitucional — Estat autonòmic.

KEYWORDS: Sustainable Development - Economic Crisis - Spanish Constitutional Court - Spanish State of Autonomies.

SUMARIO: I. Introducción. II. Marco teórico: desarrollo sostenible y crisis económica. 1. Constitucionalismo global y sistema constitucional. 2. El desarrollo sostenible como noción constitucional. III. Las tensiones en el seno de la constitución económica de un Estado social débil. IV. Actividad normativa pública y captura del legislador: la quiebra del modelo económico constitucional en tiempos de crisis V. Recentralización, neodesarrollismo y justicia constitucional. 1. El debate constitucional sobre la fractura hidráulica. 2. La política energética y las energías renovables. 3. Recentralización y regresión. VI. La necesidad de desplegar un control robusto de constitucionalidad ante la regresión normativa y la captura del legislador. VII. Conclusión. VIII. Bibliografía.

\section{INTRODUCCIÓN}

La Conferencia de las Naciones Unidas sobre el Desarrollo Sostenible que se celebró en Río de Janeiro del 20 al 22 de junio de 2012 reafirmó el compromiso de la comunidad internacional con la idea de desarrollo sostenible, declarando de entrada lo siguiente:

Nosotros, los Jefes de Estado y de Gobierno y los representantes de alto nivel, habiéndonos reunido en Río de Janeiro (Brasil) del 20 al 22 de junio de 2012, con la plena participación de la sociedad civil, renovamos nuestro compromiso en favor del desarrollo sostenible y de la promoción de un futuro sostenible desde el punto de vista económico, social y ambiental para nuestro planeta y para las generaciones presentes y futuras ${ }^{2}$.

De este modo, se confirmaba la utilización de esta noción nuclear, de esta matriz hermenéutica, en el diseño de la respuesta de la comunidad política internacional ante la crisis ambiental que se ha ido poniendo de manifiesto a lo

\footnotetext{
${ }^{2}$ Vid. Resolución aprobada por la Asamblea General el 27 de julio de 2012 (A/RES/66/288).
} 
largo de las últimas décadas, hasta suscitar, en el contexto de la constatación de la amplitud y el significado del cambio climático, la idea de transición geológica, esto es, la inauguración del Antropoceno ${ }^{3}$. Es significativo que, en el contexto de una de las crisis más graves del capitalismo - la comenzada en 2007-, la Conferencia de Río se reafirmara en la idea de desarrollo sostenible, al mismo tiempo que se hacía referencia por primera vez a "una economía verde en el contexto del desarrollo sostenible y la erradicación de la pobreza, y el marco institucional para el desarrollo sostenible"4.

Efectivamente, el desarrollo sostenible se ha convertido en el núcleo de sentido en torno al cual se articulan las respuestas políticas y jurídicas a la crisis ambiental $^{5}$. En el curso de las páginas siguientes, el objetivo es llevar a cabo un análisis crítico sobre la capacidad de esta noción fundamental de permitir una respuesta eficaz a los retos que plantea la transición hacia el Antropoceno, a partir de la consideración de cómo esta matriz conceptual se ha proyectado sobre las políticas públicas y el control jurisdiccional en España en el contexto de la crisis de $2007^{6}$. En este sentido, empezaré por clarificar el marco teórico,

${ }^{3}$ En relación con esto, vid. JARIA I MANZANO, J., "El Derecho, el Antropoceno y la justicia", Revista Catalana de Dret Ambiental, vol. 7, núm. 2, 2016.

${ }^{4}$ Vid. Resolución cit. de 27 de julio de 2012.

${ }^{5}$ Vid. JARIA I MANZANO, J., "La externalización de costes ambientales en el acceso a los recursos naturales: marco institucional y distribución inequitativa", Proyecto "Del desarrollo sostenible a la justicia ambiental: Hacia una matriz conceptual para la gobernanza global" (DER2013-44009-P), informe núm. 4, 2016, p. 39 y ss.

${ }^{6}$ La modificación significativa de las condiciones de la biosfera a causa de la actividad de origen antrópico ha sido conceptuada en términos de transición hacia una nueva era geológica, el Antropoceno, a partir del trabajo de CRUTZEN, Paul J., "Geology of mankind", Nature, vol. 415,2002 , p. 23. Esta idea no es nueva y, de hecho, el geólogo italiano Antonio Stopani ya se había referido a una era antropozoica en un momento tan temprano como 1873 (ibid.). Por su parte, el científico ruso Vladímir Vernadski había acuñado, en la primera mitad del siglo XX, la idea de noosfera, que implica un relato análogo. Sobre la figura de Vernadski, vid. SCHLÖGEL, K., Terror y utopía. Moscú en 1937, Acantilado, Barcelona, 2014 (traducción al castellano de José Aníbal Campos), p. 428 y ss. En cualquier caso, debe tenerse en cuenta que el término Antropoceno aún no ha sido aceptado de forma oficial, aunque el Grupo de Trabajo sobre el Antropoceno (AWG), formado por científicos de diferentes instituciones, presentó ante el $35 .^{\circ}$ Congreso Geológico Internacional, celebrado en Ciudad del Cabo, Sudáfrica, entre el 27 de agosto y el 4 de agosto 2016, el resumen de la evidencia disponible y su recomendación provisional para el establecimiento de una nueva edad geológica con ese nombre. En este sentido, vid. <http://www2.le.ac.uk/offices/press/press-releases/2016/august/media-noteanthropocene-working-group-awg> [consultado el 5 de mayo de 2017]. Según los trabajos del AWG, la fecha de inicio de la nueva era sería 1950. En relación con el AWG, vid. $<$ https://quaternary.stratigraphy.org/workinggroups/anthropocene/> [consultado el 5 de mayo de 2017]. Más allá de su aprobación en el contexto de un congreso geológico internacional, que es lo exigido para su aceptación oficial, es evidente que el término constituye una metáfora adecuada para describir el potencial de transformación humana sobre el entorno, la ocupación 
esto es, contextualizar la noción de desarrollo sostenible como respuesta hegemónica a la crisis ambiental y mostrar sus debilidades ${ }^{7}$.

A partir de aquí seguiré el hilo del sistema constitucional español para profundizar en estas grietas. En este contexto, es importante remarcar que el régimen constitucional de protección del medio ambiente constituye el marco fundamental en el que se desarrollan las opciones legislativas y se hacen efectivas las soluciones jurisprudenciales ${ }^{8}$. Empezaré por delimitar el contexto constitucional en el que se produce la recepción de la idea de desarrollo sostenible en España, en el marco del modelo económico de la Constitución de 1978, tal como ha sido entendido mayoritariamente por la jurisprudencia constitucional $^{9}$. Esto me servirá para fijar el escenario en el que se resuelve la

antrópica de la biosfera y la autorreferencialidad de la acción social. Ello enlaza con discursos que se han ido desplegando en las ciencias sociales desde hace unas décadas en el contexto de la toma de conciencia sobre la crisis ambiental. Vid., en este sentido, MELUCCI, A., Vivencia y convivencia. Teoría social para una era de la información, Trotta, Madrid, 2001 (edición castellana de Jesús Casquette), p. 29.

${ }^{7}$ La noción de desarrollo sostenible es una noción controvertida que, por otro lado, ha adquirido un carácter nuclear en la conceptualización de las prácticas sociales contemporáneas, incorporándose también a los fundamentos del discurso jurídico constitucional. En consecuencia, ha generado una literatura inabarcable. Sin embargo, se puede intentar citar una selección bibliográfica que dé cuenta de los debates que genera. En este sentido, vid. ALDER, J. y WILKINSON, D., Environmental Law \& Ethics, Macmillan, Londres, 1999, p. 127 y ss.; DOBSON, A., Justice and the Environment. Conceptions of Environmental Sustainability and Dimensions of Social Justice, Oxford University Press, Oxford, 1998, p. 60; JOSITSCH, D., "Das Konzept der nachhaltigen Entwicklung (Sustainable Development) im Völkerrecht und seine innerstaatliche Umweltsetzung", Umweltrecht in der Praxis / Le Droit de l'environnement dans la pratique, 1997, p. 101 y ss.; LOPERENA ROTA, D., Los principios del Derecho ambiental, Civitas, Madrid, 1998, p. 61 y ss.; y MALANCZUK, P. "Die Konferenz der Vereinten Nationen über Umwelt und Entwicklung (UNCED) und das internationale Umweltrecht", BEYERLIN, U., BOHTE, M., HOFMANN, R. y PETERSMANN, E.$U$. (eds.), Recht zwischen Umbruch und Bewahrung. Festschrift für Rudolf Bernhardt, Springer, Berlín, Heidelberg, Nueva York, 1995, p. 986 y ss.

${ }^{8}$ Vid., en este sentido, JARIA I MANZANO, J., El sistema constitucional de protecció del medi ambient, Institut d'Estudis Autonòmics, Barcelona, 2005, p. 35 y ss.

${ }^{9}$ El Tribunal Constitucional ha puesto de manifiesto la incorporación del desarrollo sostenible al marco constitucional español a través de una interpretación adaptativa que se produce a partir de la STC 102/1995, de 26 de junio, FJ $4 .^{\circ}$, en la que se afirma lo siguiente: "La conexión indicada [entre la calidad de vida en cuanto referida a la cultura y la economía y su incardinación constitucional con el medio ambiente] se hace explícita cuando se encomienda a los Poderes públicos la función de impulsar y desarrollar, se dice, la actividad económica y mejorar así el nivel de vida, ingrediente de la calidad si no sinónimo, con una referencia directa a ciertos recursos (la agricultura, la ganadería, la pesca) y a algunos espacios naturales (zonas de montaña) (artículo 130CE), lo que nos ha llevado a resaltar la necesidad de compatibilizar y armonizar ambos el desarrollo con el medio ambiente (STC 64/1982). Se trata, en definitiva del 'desarrollo sostenible', equilibrado y racional que no olvida a las generaciones futuras, alumbrado el año 1987 en el llamado Informe Bruntland, con el título 'Nuestro futuro común', encargado por la Asamblea general de las Naciones Unidas". Puede verse, en cualquier caso, 
tensión entre desarrollo y conservación del medio ambiente de acuerdo con la comprensión dominante del texto constitucional.

El sistema constitucional español, que ha sido muy receptivo a la evolución de la supraconstitución del capitalismo global, sobre todo recientemente, gracias a la combinación de un programa legislativo en sintonía con las políticas de la Unión Europea ante la crisis, se caracteriza por una exagerada deferencia del Tribunal Constitucional hacia el legislador y requiere una reforma constitucional determinante, a pesar de haber sido aprobada con una enorme celeridad, evitando el debate social - la del artículo $135 \mathrm{CE}^{10}$ - De acuerdo con este marco general, analizaré el impacto de la crisis económica de 2007 en el modelo para mostrar que el pretendido equilibrio implícito en la noción de desarrollo sostenible es más aparente que real ${ }^{11}$.

A partir de aquí, examinaré la fragilidad del marco constitucional formal, así como la actitud del máximo intérprete de la Constitución en su jurisprudencia reciente, en que ha avalado, de manera sistemática, las políticas gemelas de recentralización y desprotección ambiental surgidas en el contexto de la reacción hegemónica a la crisis financiera de $2007^{12}$. Para terminar, exploraré

que la interpretación propuesta por el Tribunal Constitucional enlaza con la perspectiva gerencial y reformista implícita en la narrativa del desarrollo sostenible.

${ }^{10}$ En relación con la idea de supraconstitución, vid. CLARKSON, S. y WOOD, S., A Perilous Imbalance. The Globalization of Canadian Law and Governance, UBC Press, Vancouver, Toronto, 2009. En cuanto a la reforma constitucional de 2011, parece evidente que ha tenido un impacto notable que supone una reconfiguración de la propia forma del Estado, particularmente en lo que respecta a su faceta social. En este sentido, Albert NOGUERA FERNÁNDEZ, en La igualdad ante el fin del Estado Social. Propuestas constitucionales para construir una nueva igualdad, Sequitur, Madrid, 2014, p. 113, ha señalado que implicaría "[l]a constitucionalización de la obligación de las Administraciones públicas de tener que dar 'prioridad absoluta' en sus presupuestos al pago de los intereses y del capital de la deuda pública sobre otras inversiones, aunque con ello se sacrifiquen otros objetivos o derechos constitucionales como la protección social". Vid., asimismo, sobre esta cuestión, CABO MARTín, C. de, Pensamiento crítico, constitucionalismo crítico, Trotta, Madrid, 2014, p. 83. No voy a ocuparme en detalle sobre esta reforma, pero va a formar parte del trasfondo sobre el que se construye el discurso principal aquí desplegado.

${ }^{11}$ Vid. CARDESA-SALZMANN, A., COCCIOLO, E. y JARIA I MANZANO, J., "Whither Sustainable Development? The Global Economic System's Contribution to Sustain Ecologically Unequal Exchange", Proyecto "Del desarrollo sostenible a la justicia ambiental: Hacia una matriz conceptual para la gobernanza global" (DER2013-44009-P), informe núm. 7, 2016, p. 8 y Ss.

${ }^{12}$ En efecto, "el Tribunal Constitucional muestra una absoluta reserva en relación con las consideraciones ecosistémicas necesarias en cualquier política ambiental razonable, lo que lo lleva a sostener una fragmentación competencial que acaba derivando en una opción desarrollista de escasa sensibilidad ambiental", como se ha puesto de manifiesto en relación con los problemas planteados por la fractura hidráulica. Vid. JARIA I MANZANO, J., 
cómo el Tribunal Constitucional hubiera podido ejercer un papel más contundente en la defensa de las condiciones de reproducción de la base biofísica de la sociedad, así como en la implantación de mecanismos efectivos tendentes a avanzar hacia un modelo de justicia ambiental ${ }^{13}$.

\title{
II. MARCO TEÓRICO: DESARROLLO SOSTENIBLE Y CRISIS ECONÓMICA
}

\section{En el contexto de un estudio prospectivo de carácter general sobre la situación} y las expectativas del derecho ambiental en España, desde la perspectiva de los fundamentos constitucionales del sistema, se hace necesario delimitar el punto de partida, esto es, la matriz constitucional que determina la respuesta a la configuración institucional del metabolismo social ${ }^{14}$. Por otro lado, debe

\begin{abstract}
"Jurisprudencia constitucional en materia de protección del medio ambiente (primer semestre 2016)", Revista Catalana de Dret Ambiental, vol. 7, núm. 1, 2016, p. 21. En general, sobre la jurisprudencia constitucional en esta materia, vid. SANTAMARÍA ARINAS, R. J., "Las claves jurídicas del debate sobre el fracking", Revista Catalana de Dret Ambiental, vol. 5, núm. 1, 2014.

${ }^{13}$ Parto de la diferenciación entre justicia ambiental y desarrollo sostenible como matrices diferenciadas en la articulación de una respuesta social a la crisis ambiental. Esta era la tesis que sostenía el proyecto "Del desarrollo sostenible a la justicia ambiental: Hacia una matriz conceptual para la gobernanza global", financiado por el Ministerio de Economía y Competitividad para el período 2014-2016 (referencia: DER2013-44009-P; investigador principal: Antoni Pigrau Solé), en el que el autor tomó parte. Sobre el sentido de esta diferenciación y sus consecuencias, vid. JARIA I MANZANO, J., "El constitucionalismo de la escasez (derechos, justicia y sostenibilidad)", Revista Aranzadi de Derecho Ambiental, núm. 30, 2015, pp. 295-349.
\end{abstract}

${ }^{14}$ La idea teórica fundamental a la hora de plantear este trabajo es que la constitución delimita el contexto institucional del metabolismo social. El concepto de metabolismo social constituye una metáfora biológica que se incorpora al discurso de las ciencias sociales a través de la obra de Karl Marx -la expresión alemana es Stoffwechsel-. Marx había configurado esta noción a partir de las lecturas biológicas que había efectuado, entre las que tiene particular importancia la obra de Jacob Moleschott. Vid., en relación con ello, TOLEDO, V. M., "EI metabolismo social: una nueva teoría socieconómica", Relaciones, núm. 136, 2013, pp. 42-43. Para Marx, el metabolismo es una metáfora que se despliega en múltiples sentidos, refiriéndose en ocasiones a intercambios en el seno de la economía capitalista y, por lo tanto, en el interior de la sociedad. En cualquier caso, el uso de la expresión en el sentido de intercambio entre naturaleza y sociedad puede encontrarse, asimismo, en la obra marxiana. Así, por ejemplo, vid. MARX, K., El Capital (Libro I - Tomo I), Akal, Tres Cantos, 2000 (2. ${ }^{a}$ edición castellana a cargo de Vicente Romano García), p. 65. En el ámbito de la economía ecológica contemporánea, la idea de metabolismo social ha adquirido una significativa centralidad teórica. Vid. FISCHERKOWALSKI, M., "Society's Metabolism: The Intellectual History of Materials Flow Analysis, Part I, 1860-1970", Journal of Industrial Ecology, vol. 2, núm. 1, 1998, pp. 61-78; FISCHERKOWALSKI, M. y HÜTTLER, W., "Society's Metabolism: The Intellectual History of Materials Flow Analysis, Part II, 1980-1998", Journal of Industrial Ecology, vol. 2, núm. 4, 1998, pp. 107136; y WEISZ, H., "Combining Social Metabolism and Input-Output Analysis to Account for Ecologically Unequal Trade", HORNBORG, A., MCNEILL, J. R. y MARTíNEZ-ALIER, J. (eds.), Rethinking Environmental History: World-System History and Global Environmental Change, AltaMira Press, Lanham, pp. 289-306. El marco normativo del metabolismo social se correspondería con la noción bien establecida de constitución económica. Sobre la constitución 
tenerse en cuenta que los procesos de reproducción social, en el contexto de la fase financiera del capitalismo tardío y el desarrollo de nuevas tecnologías de la información y la comunicación, han adquirido una dimensión global que se corresponde con redes de intercambio social de ámbito planetario, lo que ha de tener necesariamente consecuencias a la hora de construir el marco constitucional apropiado $^{15}$.

\section{Constitucionalismo global y sistema constitucional}

Pues bien, de acuerdo con las necesidades hermenéuticas que afloran en el contexto del constitucionalismo del capitalismo tardío, cabe aludir a la idea de constitucionalismo global. Esta noción responde en un doble sentido a la evolución del contexto normativo de la economía-mundo capitalista ${ }^{16}$. Por una

económica, vid. ALBERTí ROVIRA, E., Autonomía política y unidad económica, Civitas, Madrid, 1995, p. 177 y ss.; BARBANCHO TOVILLAS, F. J., Evolución del pensamiento económico y el Derecho civil: ensayo para su enseñanza, Signo, Esplugues de Llobregat, 1991, p. 77 y ss.; BASSOLS COMA, M., Constitución y sistema económico, Tecnos, Madrid, 1985; CUADRA SALCEDO, T. de la, "La Constitución económica de España. Comentario introductorio al Título VII", ALZAGA VILLAAMIL, Ó. (dir.), Comentarios a la Constitución española de 1978 (X), Edersa, Madrid, 1998, pp. 15-44; LÓPEZ GARRIDO, D., "Apuntes para un estudio sobre la Constitución económica", Revista del Centro de Estudios Constitucionales, núm. 15, 1993, pp. 79-96; y POYAL COSTA, A., Normas constitucionales y realidad. Análisis de su intervención transformadora, UNED, Madrid, 1995, p. 139 y ss.

${ }^{15}$ Vid. HELD, D., MCGREW, A., GOLDBLATT, D. y PERRATON, J., Global Transformations. Politics Economics and Culture, Polity, Cambridge, 1999, p. 15. Este desajuste entre la economía-mundo capitalista de alcance global y la constitución formal de dimensión nacional debe afrontarse a través de un discurso nacional que integre esta última en un marco más amplio. En este sentido, "Constitution', then, becomes an anchoring point and reference perspective for the collision of existing and emerging legal semantics of society's selfgovernance. But, as such, the constitution is no longer a 'public law' text, emanating form state authority and sitting at the pinacle of a pyramid of legal normativity. Instead, constitutions written and unwritten - and constitucional law must facilitate the intersection of law and politics in a radically heterarchic, modern society" (vid. ZUMBASEN, P. "Carving our typologies and Accounting for differences across Systems: towards a methodology of transnational constitutionalism", ROSENFELD, M. y SAJÓ, A., The Oxford Handbook of Comparative Constitutional Law, Oxford University Press, Oxford, 2012, p. 96). El discurso que se desarrolla a continuación se inscribe en el intento de construir un marco constitucional adecuado para el control de las decisiones de los poderes públicos capturados en el contexto de la globalización capitalista, para lo que, previamente, se formula una crítica sobre los patrones formalistas utilizados hasta el momento por parte del Tribunal Constitucional español en su "jurisprudencia de la crisis", por llamarla de algún modo.

${ }^{16}$ La teoría de los sistemas-mundo ha sido desarrollada por Immanuel Wallerstein a lo largo de su obra, particularmente en la trilogía dedicada al despliegue del sistema-mundo capitalista. Vid., este sentido, WALLERSTEIN, I., El moderno sistema mundial. I. La agricultura capitalista y los orígenes de la economía-mundo en el siglo XVI, Siglo XXI, Madrid, 2010 (2. ${ }^{\text {a }}$ edición castellana a cargo de Antonio Resines). De acuerdo con el propio Wallerstein, debe distinguirse entre economía-mundo e imperio-mundo. El segundo implica la existencia de un único centro de imputación político, que genera las reglas y las estructuras institucionales adecuadas para 
parte, se compadece con la constatación de la progresiva consolidación de un espacio constitucional global, a partir de la evolución del derecho internacional, que incide en el despliegue del derecho constitucional tradicional, delimitado por el espacio del estado-nación ${ }^{17}$. Por otra, más allá de ello, cabe constatar las potenciales innovaciones que pueden producirse para avanzar hacia un sistema de gobernanza sintonizado con las dinámicas globales del metabolismo social que integre elementos de equidad y habilite instrumentos efectivos de control del poder ${ }^{18}$.

De acuerdo con la idea de espacios normativos diversos y superpuestos, que parece ser coherente con la evolución de los procesos de reproducción social en el seno de la economía-mundo capitalista, se han desplegado distintas aproximaciones teóricas que vienen a constituir el substrato del constitucionalismo global como nuevo paradigma en la construcción del discurso constitucional ${ }^{19}$. Pues bien, el punto de partida teórico para el análisis

permitir las relaciones de intercambio. La economía-mundo, en cambio, funciona a través de una estructura institucional descentralizada que permite avanzar en el despliegue de las relaciones de intercambio en espacios sociales cada vez más amplios. En este contexto, la economía-mundo sería la forma capitalista específica del sistema-mundo, que se estructuraría en torno a las relaciones económicas, mientras que la estructura institucional sería fragmentaria. Vid. op. cit., p. 21.

${ }^{17}$ Este es el planteamiento que gravita en torno a la idea de supraconstitución, a la que ya me he referido, manejada por Clarkson y Wood en A Perilous Imbalance... cit. La supraconstitución se referiría más bien a la estructura normativa internacional que sostiene institucionalmente la economía-mundo capitalista que no al derecho internacional de mayor densidad axiológica, como sería el caso de los derechos humanos o el derecho internacional del medio ambiente. Esto coincidiría con la captura del legislador en el contexto estatal a causa de la dependencia del Estado de la legitimación que obtiene a través de sus políticas de gasto, sustentadas en su acceso a los mercados internacionales de capitales. Esta perspectiva es fundamental en la concepción del trabajo aquí presentado. En este sentido, la jurisprudencia constitucional analizada respondería a un "constitucionalismo global" alineado con la economía-mundo capitalista que ampararía marcos constitucionales nacionales favorables a las estrategias internacionales de apropiación y distribución de recursos.

${ }^{18}$ Este podría ser el camino abierto por lo que se ha denominado constitucionalismo ambiental global. Vid. KOTZÉ, L. J., "Arguing Global Environmental Constitutionalism", Transnational Environmental Law, núm. 1, 2012, pp. 199-233.

${ }^{19}$ Así, ante la progresiva porosidad del derecho constitucional tradicional a los desarrollos internacionales, tanto en el ámbito global como en el regional, así como ante la progresiva consolidación de un derecho constitucional subestatal, se ha desarrollado la idea de un constitucionalismo multinivel. Vid. PERNICE, I. y KANITZ, R., Fundamental Rights and Multilevel Constitutionalism in Europe, Walter Hallstein-Institut Paper, marzo de 2004. También puede hablarse de constitucionalismo en red, que da una impresión más precisa y menos jerárquica de lo que sucede actualmente en el progresivo desarrollo de centros distintos de producción normativa de dimensión constitucional, difícilmente reconducibles a una unidad sistémica. A esta toma de conciencia en la tradición del derecho constitucional de los nuevos desarrollos que exige la globalización, cabe añadir una concienciación paralela en el ámbito del derecho internacional público, en cuyo contexto se ha hablado de constitucionalización. Vid., en 
que voy a realizar a continuación es la existencia de una realidad constitucional proteica y lábil que se proyecta sobre los centros de producción normativa e impregna las distintas jurisdicciones constitucionales ${ }^{20}$. Esta realidad, a mi juicio, puede concebirse en términos de legitimación de las estrategias de apropiación y distribución en el contexto de la economía-mundo capitalista, o bien evolucionar hacia patrones robustos de control del poder que impugnen las regulaciones resultantes de las mencionadas estrategias en términos contramayoritarios, de acuerdo con el propio fundamento de la jurisdicción constitucional $^{21}$.

A partir de esta idea, puede razonarse en términos de sistema constitucional, de modo que no debe reducirse el núcleo del Estado de derecho a la constitución en sentido formal, sino que se expande hacia normas de origen internacional, supranacional e infraestatal ${ }^{22}$. El sistema constitucional aparece aquí como un conjunto de normas con vocación constitucional, una constelación de normas que se ordenan ante el problema concreto para desplegar el derecho constitucional de modo funcional en el acto de la interpretación del derecho y permitir el control del poder ${ }^{23}$. De cómo se articule

particular, KLABBERS, J., PETERS, A. y ULFSTEIN, G., The Constitutionalization of International Law, Oxford University Press, Oxford, 2009.

${ }^{20}$ Así, Armin von Bogdandy, en "Comparative Constitutional Law: A Contested Domain. A. Comparative Constitutional Law: A Continental Perspective", ROSENFELD, SAJÓ, The Oxford Handbook... cit., p. 26, ha señalado que "[w]hereas the constitution was formerly conceived as creating a normative universe, it is now increasingly understood as being but a part of a normative pluriverse, pushing towards comparison".

${ }^{21}$ La idea del control de constitucionalidad es determinante en este contexto, en la medida que somete el poder a los procesos y lo circunscribe a los límites que la propia constitución establece. Vid., en este sentido, VERDÚ, P. L., "Estado de Derecho y justicia constitucional. Aspectos históricos, ideológicos y normativo-institucionales de su interrelación", Revista de Estudios Políticos, núm. 33 (nueva época), 1983, pp. 7-48.

${ }^{22}$ Cabe traer a colación aquí la reflexión del Tribunal Constitucional en la STC 98/2012, de 6 de noviembre (FJ 9. ${ }^{\circ}$ ), que se expresaba en los términos siguientes: "Pues bien, la cultura jurídica no se construye sólo desde la interpretación literal, sistemática u originalista de los textos jurídicos, sino que también contribuyen a su configuración la observación de la realidad social jurídicamente relevante, sin que esto signifique otorgar fuerza normativa directa a lo fáctico, las opiniones de la doctrina jurídica y de los órganos consultivos previstos en el propio ordenamiento, el Derecho comparado que se da en un entorno socio-cultural próximo y, en materia de la construcción de la cultura jurídica de los derechos, la actividad internacional de los Estados manifestada en los tratados internacionales, en la jurisprudencia de los órganos internacionales que los interpretan, y en las opiniones y dictámenes elaboradas por los órganos competentes del sistema de Naciones Unidas, así como por otros organismos internacionales de reconocida posición".

${ }^{23}$ Vid. ZAGREBELSKY, G., El derecho dúctil. Ley, derechos, justicia, Trotta, Madrid, 1995 (versión castellana a partir del original italiano a cargo de Marina Gascón), p. 114 y ss. 
el mencionado sistema constitucional en el acto concreto de selección e interpretación del derecho aplicable al caso concreto, pueden derivarse opciones muy distintas para el juez de la constitucionalidad ${ }^{24}$.

\section{El desarrollo sostenible como noción constitucional}

El desarrollo sostenible se configura como la idea fundamental para la asimilación de la crisis ambiental en el contexto del lenguaje jurídico hegemónico, de acuerdo con los patrones propios del sistema de valores del derecho internacional, intentando conjugar las aspiraciones de los países de la periferia de la economía mundial, articuladas en torno el derecho al desarrollo, con la nueva sensibilidad ambiental de las sociedades centrales, sin incidir en la estructura institucional del capitalismo global y su favorecimiento de la desregulación creciente en materia de comercio e inversiones ${ }^{25}$. De este modo, desde el punto de vista de un discurso constitucional global, el desarrollo sostenible deviene una noción fundamental que se proyecta sobre los derechos constitucionales locales y que, como veremos, particularmente, informa la orientación de la jurisprudencia constitucional en España en relación con el marco regulador del metabolismo social ${ }^{26}$.

Efectivamente, la idea del desarrollo sostenible subyace en la estructuración de los principios del derecho internacional del medio ambiente desde la Declaración de Río de Janeiro sobre el Medio Ambiente y el Desarrollo (1992), encontrando un fácil acomodo constitucional en el ámbito español a través de

\footnotetext{
${ }^{24}$ Vid. JARIA I MANZANO, J., "La identificación del Derecho aplicable en un contexto normativo complejo", VV. AA., Diálogos sobre la justicia y los jueces, Centre d’Estudis Jurídics i Formació Especialitzada, Barcelona, 2015, p. 102 y ss.

${ }^{25}$ Vid. JARIA I MANZANO, "El constitucionalismo de la escasez..." cit., p. 301 y ss. En relación con la diferenciación centro-periferia, parto de su carácter estructural en la articulación de la economía-mundo capitalista. Vid., en este sentido, TAYLOR, Peter J. y FLINT, Colin, Geografía política. Economía-mundo, estado-nación y localidad, Trama, Madrid, 2002 (2. a edición castellana a cargo de Adela Despujol Ruiz-Jiménez y Heriberto Cairo Carou), p. 21 y ss.

${ }^{26}$ En este contexto, cabe recordar que el desarrollo sostenible se define como aquel que "asegura las necesidades del presente sin comprometer la capacidad de las futuras generaciones para enfrentarse a sus propias necesidades". Vid. COMISIÓN MUNDIAL DEL MEDIO AMBIENTE Y DEL DESARROLLO, Nuestro futuro común, Alianza Editorial, Madrid, 1988, p. 29.
} 
la combinación de diferentes preceptos constitucionales ${ }^{27}$. La articulación de los elementos normativos del metabolismo social global en torno al desarrollo sostenible se consolida en el documento final de la Conferencia de las Naciones Unidas sobre el Desarrollo Sostenible (2012), "El futuro que queremos", que propugna la economía verde como concepto central en el marco de una presión desarrollista aumentada por el escenario de crisis económica profunda que se ha enquistado desde $2008^{28}$. La eficiencia y el crecimiento económicos, que, junto con la protección del medio ambiente y la solidaridad social, son elementos constitutivos de la noción de desarrollo sostenible, van ganando peso ante los demás ejes en torno a los cuales gravita la idea, desvelando el sentido de tal idea en el marco conceptual del capitalismo tardío ${ }^{29}$.

Con ello, el paradigma del desarrollo sostenible muestra con claridad que responde al ethos burgués, consolidando un modelo social que se basa en la explotación masiva de los recursos naturales para satisfacer las necesidades de la sociedad de consumo, lo que incrementa la presión sobre las periferias

\footnotetext{
${ }^{27}$ Vid., en este sentido, la STC 102/1995, de 26 de junio, FJ $4 .^{\circ}$. Cabe señalar aquí, fundamentalmente, los artículos 40, 45 y $130 \mathrm{CE}$.

${ }^{28}$ Cabe traer a colación aquí el párrafo 62 del mencionado documento final, en el que, de modo significativo, se proclama:
}

\begin{abstract}
Alentamos a cada país a que considere la posibilidad de implantar políticas de economía verde en el contexto del desarrollo sostenible y la erradicación de la pobreza, de manera que se procure impulsar un crecimiento económico y una creación de empleo sostenidos, inclusivos y equitativos, en particular para las mujeres, los jóvenes y los pobres. A este respecto, observamos la importancia de asegurar que los trabajadores adquieran los conocimientos técnicos necesarios, incluso por medio de la educación y la creación de capacidad, y reciban la protección social y de la salud que necesitan. A este respecto, alentamos a todos los interesados, incluidas las empresas y la industria, a que contribuyan, según proceda. Invitamos a los gobiernos a que mejoren sus conocimientos y su capacidad estadística en lo que respecta a las tendencias, la evolución y las restricciones en materia de empleo e incorporen datos pertinentes en las estadísticas nacionales, con el apoyo de los organismos competentes de las Naciones Unidas conforme a sus mandatos.
\end{abstract}

En definitiva, el documento despliega una interpretación de desarrollo sostenible en la que claramente se prioriza uno de los tres vectores pretendidamente integrados en la noción, esto es, la idea de desarrollo económico, por encima de los de protección del medio ambiente o de justicia social.

${ }^{29}$ Sobre el triple eje en torno al que gravita, originariamente, la noción de desarrollo sostenible, vid. JOSITSCH, "Das Konzept..." cit., p. 117. 
del sistema y externaliza los costes ambientales ${ }^{30}$. Todo ello genera, sobre todo en la periferia del sistema-mundo capitalista, una pulsión por el desarrollo en los términos impuestos por el discurso hegemónico que compromete las políticas de protección en un contexto de intercambio desigual ${ }^{31}$. En este contexto se estimula, en el mejor de los casos, la puesta a disposición de los recursos naturales para obtener la financiación necesaria para avanzar en frágiles políticas sociales ${ }^{32}$. Este patrón explica la erosión de las políticas ambientales en España desde el inicio de la crisis económica ${ }^{33}$.

\section{LAS TENSIONES EN EL SENO DE LA CONSTITUCIÓN ECONÓMICA DE UN ESTADO SOCIAL DÉBIL}

El hecho de que la sustancia constitucional de la protección del medio ambiente, en el contexto complejo al que acabamos de referirnos, se articule en torno a la idea fundamental de desarrollo sostenible favorece el despliegue de un programa legislativo que responde a los elementos fundamentales del sistema constitucional hegemónico, imponiendo una agenda gerencial y desarrollista coherente con la caracterización del Estado en la tradición constitucional reciente ${ }^{34}$. Efectivamente, dentro de los esquemas clásicos del

\footnotetext{
${ }^{30}$ En este sentido, vid. ALTVATER, E., El precio del bienestar, Alfons el Magnànim, Valencia, 1994 (versión castellana de Manuel Ardid Lorés), p. 188. En relación con el ethos burgués y la idea del homo œconomicus como fundamento de la economía política y de la cultura del capitalismo, vid. BUCK-MORSS, S., "Envisioning Capital: Political Economy On Display", COOKE, L. y WOLLEN, P. (eds.), Visual Display. Culture Beyond Appereances, Bay Press, Seattle, 1995, p. 136.

${ }^{31}$ Vid. TIMMONS ROBERTS, J. y PARKS, B. C., "Ecologically Unequal Exchange, Ecological Debt, and Climate Justice. The History and Implications of Three Related Ideas for a New Social Movement", International Journal of Comparative Sociology, vol. 50, núms. 3-4, 2009, p. 389.

${ }^{32}$ Ello se da, con particular virulencia, en la periferia del sistema, como pone de manifiesto, para Ecuador, ECHEVERRÍA, J., "Complejización del campo político en la construcción democrática en el Ecuador", BURBANO DE LARA, F. (coord.), Transiciones y rupturas. EI Ecuador en la segunda mitad del siglo XX, FLACSO, Sede Ecuador, Quito, 2010, p. 105, que se refiere a "la lógica extractivista del modelo primario exportador".

${ }^{33}$ Vid. NOGUEIRA LÓPEZ, A., BORRÀS PENTINAT, S., GILES CARNERO, R. y JARIA I MANZANO, J., "Marco general. El medio ambiente en los tiempos de globalización neoliberal", SANZ LARRUGA, F. J. y PERNAS GARCÍA, J. J. (dirs.), SÁNCHEZ, J. (coord.), Derecho ambiental para una economía verde. Informe ECOVER, Thomson Reuters-Aranzadi, Cizur Menor, 2016, pp. 21-48.

${ }^{34}$ En este sentido, vid. BOSSELMANN, K., The Principle of Sustainability. Transforming Law and Governance, Ashgate, Farnham, Burlington, 2008, p. 116.
} 
derecho constitucional del siglo $\mathrm{XX}$, centrados en torno a la constitución del Estado social, la protección del medio ambiente se configuraba como un bien jurídico constitucional que justificaba la intervención normativa del Estado en el despliegue de las fuerzas económicas en el mercado ${ }^{35}$.

Así, una primera interpretación de la introducción de cláusulas de protección del medio ambiente en las constituciones nacionales - fueran o no en forma del reconocimiento de un derecho a un medio ambiente sano o adecuado- se operaba de acuerdo con marcos hermenéuticos desarrollados en el discurso del derecho constitucional del Estado social -por ejemplo, la función social de la propiedad, reconocida en el artículo 33.2 CE, que responde a una larga tradición iniciada con el famoso "la propiedad obliga" del artículo 153 de la Constitución de la República de Weimar ${ }^{36}$ _. En este contexto, el artículo 45 $\mathrm{CE}$, en relación con el artículo 53.3 CE, se presentaba, más allá de su condición de clave hermenéutica y parámetro de control de constitucionalidad, sobre todo y fundamentalmente como una habilitación para los poderes públicos en el sentido de introducir limitaciones constitucionalmente justificadas a las libertades económicas ${ }^{37}$.

Sin embargo, cabe referirse aquí a una doble tensión. Por una parte, en el marco del Estado social tradicional, las libertades económicas coliden con las limitaciones que se derivan de la necesidad de garantizar un mínimo existencial para los miembros de la comunidad ${ }^{38}$. Por otra, cabe señalar que se produce

\footnotetext{
${ }^{35}$ Vid. JARIA I MANZANO, El sistema constitucional... cit., p. 45.

${ }^{36}$ Sobre la función social de la propiedad, vid. HERNÁNDEZ GIL, A., "La propiedad privada y su función social", Poder Judicial, núm. 14 (segunda época), 1989, pp. 9-22; LÓPEZ Y LÓPEZ, Á. M., La disciplina constitucional de la propiedad privada, Tecnos, Madrid, 1988, p. 55 y ss.; SIERRA PÉREZ, P., Obligaciones "propter rem" hoy: los gastos comunes en la propiedad horizontal, Tirant lo Blanch, Valencia, 2002, pp. 27-28. Sobre el artículo 151.2 de la Constitución de Weimar, vid. POLAKIEWICZ, J., "El proceso histórico de implantación de los derechos fundamentales en Alemania", Revista de Estudios Políticos, núm. 81 (nueva época), 1993 , p. 32. Sobre la protección del medio ambiente como elemento integrador de la función social de la propiedad, vid. AGUILERA VAQUÉS, M., El desarrollo sostenible y la Constitución Española, Atelier, Barcelona, 2000, p. 200.

${ }^{37}$ Vid. JARIA I MANZANO, J., "Derechos y medio ambiente", NOGUERA FERNÁNDEZ, A. y GUAMÁN HERNÁNDEZ, A., Lecciones sobre Estado social y derechos sociales, Tirant lo Blanch, Valencia, 2014, p. 590.

${ }^{38}$ En definitiva, como señala Miguel Ángel Aparicio Pérez en Introducción al sistema político y constitucional español, Ariel, Barcelona, 1991 (5. ${ }^{\text {a }}$ edición), p. 91, el Estado social se caracterizaría por la garantía de un bienestar mínimo para todos y la corrección del libre funcionamiento de las fuerzas del mercado a través de la intervención del Estado para conseguir esa finalidad. En este contexto, se establecerían limitaciones a la libertad personal
} 
una tensión entre el programa tradicional del Estado social, centrado en la generalización de unas condiciones de vida de acuerdo con el ethos burgués, que implica el despliegue de estrategias de explotación intensiva de los recursos naturales y de uso masivo de la naturaleza como repositorio de los residuos del metabolismo social, y la propia protección del medio ambiente ${ }^{39}$. Esta doble tensión entra en juego en el contexto de las respuestas mayoritarias a la crisis económica y, en el contexto de la transición hacia el Antropoceno, pone en juego los elementos fundamentales del sistema.

En el caso español, hay que señalar que la implantación del Estado social a partir de 1978 se produce ya en un contexto de crisis — seguramente la primera que tiene una lectura ambiental, ya que se produce en relación con la disponibilidad y el precio de un recurso natural básico, a saber, el petróleo—, lo que, en definitiva, condiciona que adolezca de una cierta fragilidad que se

individual con el objeto de garantizar el disfrute de esa libertad por todos los miembros de la comunidad a través del aseguramiento de unas determinadas condiciones de vida. Vid. GETHMANN, K. F., "Individuelle Freiheit und Umweltschutz aus philosophischer Sicht", KLOEPFER, M. (ed.), Umweltstaat als Zukunft, Economica, Bonn, 1994, p. 42.

${ }^{39}$ Vid. MURSWIEK, D., Umweltschutz als Staatszweck, Economica, Bonn, 1995, p. 48. En relación con esto, Luzius Wildhaber, en "Soziale Grundrechte", SALADIN, P. y WILDHABER, L. (eds.), Der Staat als Ausgabe. Gedenkschrift für Max Imboden, Helbing \& Lichtenhahn, BasileaStuttgart, 1972, p. 373, señala que el Estado social no impugna los fundamentos del Estado liberal clásico, sino que solo obliga a replantear el reconocimiento de una libertad económica absoluta, justamente para extender los derechos al conjunto de la comunidad política. Así, por una parte, la protección del medio ambiente se integra en el contexto del Estado social, dada la coincidencia de técnicas que implica con su configuración clásica, sobre todo en relación con la limitación de las libertades económicas. Vid., en este sentido, ASENSI SABATER, J., Constitucionalismo y Derecho constitucional, Tirant lo Blanch, Valencia, 1996, p. 117. Sin embargo, por otra, se produce una cierta divergencia de fondo, que se concreta en la tensión entre la necesidad de explotación de los recursos naturales para satisfacer las demandas sociales en el marco del Estado social, que obtiene el principio de su legitimidad proporcionando un bienestar mínimo para todos concebido en términos de capacidad básica de consumo, y la preservación de dichos recursos. Vid., en relación con ello, CROOK, S., PATULSKI, J. y WATERS, M., Postmodernization. Change in Advanced Society, Sage, Londres, Thousand Oaks, Nueva Delhi, 1992, p. 86. En este sentido, la idea del derecho al desarrollo en el contexto internacional, que se encuentra en la base del concepto de desarrollo sostenible, se emparenta con el Estado social en la medida que ambas nociones son dependientes del crecimiento económico, al menos en su acepción habitual. La tensión entre desarrollo y protección del medio ambiente se evidencia en el despliegue de las constituciones andinas de la década anterior (Ecuador, 2008; Bolivia, 2009), donde la innovación en materia ambiental se da al mismo tiempo que una aceleración del extractivismo. En el caso boliviano, por tomarlo como ejemplo, la Constitución de 2009 sigue al triunfo del Movimiento al Socialismo (MAS), que tiene su origen en el movimiento cocalero del Trópico de Cochabamba, cuya aspiración es justamente expandir la tierra agrícola en la zona, en un programa inequívocamente desarrollista, lo que acabará proyectándose tanto en el texto constitucional como en su desarrollo. Vid., en este sentido, CASTILLO, M. y DURAND, A., "Movimiento cocalero, política y representación: los casos boliviano y peruano", GARCÍA, F. (comp.), Identidades, etnicidad y racismo en América Latina, FLACSO, Quito, 2008, p. 60 y ss. 
proyecta sobre su construcción dogmática y su efectividad práctica ${ }^{40}$. Ello condiciona la virtualidad de la utilización de las herramientas del Estado social clásico en el control de la actividad económica privada y, posteriormente, la resiliencia del sistema ante las políticas de retirada del sector público en el contexto de la crisis económica.

Efectivamente, a partir de un Estado autoritario, la implantación de la democracia en España supone un avance hacia el Estado social, de acuerdo con los consensos básicos de la Transición ${ }^{41}$. Sin embargo, los mecanismos de protección social preexistentes, de acuerdo con las bases constitucionales del liberalismo doctrinario y el corporativismo católico que estructuraban económicamente el Estado franquista, eran endebles, mientras que la protección del medio ambiente era algo que había aparecido tímidamente hacia

\footnotetext{
${ }^{40}$ Para un análisis del horizonte teleológico del Estado social y las dificultades para configurarlo jurídicamente en el contexto español, vid. GARCÍA HERRERA, M. Á. y MAESTRO BUELGA, G., "Regulación constitucional y posibilidad del Estado social", Revista Vasca de Administración Pública, núm. 22, 1988, pp. 87-115. Miguel Ángel APARICIO PÉREZ, en "El Estado social en la jurisprudencia del Tribunal Constitucional", CÁMARA VILLAR, G. y CANO BUESO, J. (eds. y coords.), Estudios sobre el Estado Social. Estado Social y Comunidad Autónoma de Andalucía, Tecnos, Madrid, 1993, p. 61, señala que, en la práctica jurisprudencial, puede atribuirse una eficacia meramente "semántica" a la cláusula de Estado social. Sobre esta cuestión, vid., asimismo, PÉREZ ROYO, J. "La doctrina del Tribunal Constitucional sobre el Estado Social", Revista Española de Derecho Constitucional, núm. 10, 1984, pp. 157-181.

${ }^{41}$ Debe tomarse en cuenta aquí que el consenso constitucional vino precedido de los llamados Pactos de la Moncloa, de 1977, que constituyeron el marco económico en el que se desarrolló el proceso constituyente y vinieron a determinar las posibilidades del despliegue del Estado social en el nuevo texto constitucional, en el contexto de la gravísima crisis de 1973. En relación con dichos acuerdos, vid. CABRERA, M., "Los Pactos de La Moncloa: acuerdos políticos frente a la crisis", Historia y Política, núm. 26, 2011, pp. 81-110. Así, el Estado social español se implanta en el momento en el que en el resto de Europa se comienza a hablar de su crisis, derivada de las dificultades de financiación que se han producido a raíz de la crisis del petróleo y de la propia evolución de la economía financiera a partir de elementos liberalizadores del sistema que empiezan a implantarse a partir de la quiebra de Bretton Woods. Efectivamente, como señalan HELD, MCGREW, GOLDBLATT y PERRATON en Global Transformations... cit., p. 201, la crisis del petróleo y el colapso del sistema de Bretton Woods, junto con la emergencia del mercado de eurodivisas, señalan la transición hacia la economía-mundo financiera, lo que comportará el correlativo debilitamiento de los Estados. Desde entonces, las diferencias entre los sectores más ricos y los más pobres de la población mundial han tendido a crecer, revirtiendo la tendencia que había impulsado el Estado social. Paul Krugman ha descrito este proceso como la Gran Divergencia. Vid. FONTANA, P., Por el bien del imperio. Una historia del mundo desde 1945, Pasado \& Presente, Barcelona, 2011, p. 565. Ello contrasta con la expansión de la sociedad de consumo y del Estado del bienestar en las décadas anteriores. Para una descripción de ello, vid. MAZOWER, M., Der dunkle Kontinent. Europa im 20. Jahrhundert, Fischer, Frankfurt am Main, 2000 (versión alemana de Hans-Joachim Maass), p. 425 y ss.
} 
principios de los setenta con la Ley 38/1972, de 22 de diciembre, de protección del ambiente atmosférico ${ }^{42}$.

Todo ello va a condicionar la virtualidad de las posibilidades constitucionales derivadas de la interrelación entre el reconocimiento de libertades económicas y su limitación a causa de la protección de intereses sociales, que van a desplegarse en un entorno progresivamente desfavorable que se agrava con la crisis económica de 2007, en el marco de la financiarización creciente de la economía $^{43}$. Con ello, se produce el progresivo desmantelamiento de las estructuras emergentes de un Estado social en ciernes, centradas en la provisión de servicios por parte del sector público y la existencia de un marco regulatorio que permitía el control social de la actividad económica privada ${ }^{44}$.

Con la existencia de una presión progresiva sobre los actores públicos en el sentido de deconstruir el programa social de la Constitución y ampliar los márgenes de las libertades económicas, tiende a producirse un desequilibrio entre las libertades económicas y la protección de bienes jurídicos colectivos, entre los que cobra cada vez más importancia el medio ambiente, sometido a una presión creciente por las necesidades de crecimiento que derivan de la búsqueda de legitimación social de las estructuras públicas en un contexto de financiación cada vez más hostil ${ }^{45}$. Así, mientras que las bases de la legitimidad

\footnotetext{
${ }^{42}$ Así, la Ley de Principios del Movimiento Nacional, de 17 de mayo de 1958, proclamaba, en su Principio IX: "El ideal cristiano de la justicia social, reflejado en el Fuero del Trabajo, inspirará la política y las leyes".

${ }^{43}$ El caso de la vivienda es especialmente significativo, teniendo en cuenta el escaso impacto que ha tenido el reconocimiento del derecho a una vivienda digna recogido en el artículo 47 de la Constitución en el mercado inmobiliario y en el acceso real a la vivienda, de manera que la inyección de capital en un contexto especulativo ha hinchado los precios hasta provocar una escasez de vivienda disponible que se contradice con la disponibilidad efectiva pero bloqueada por razón del precio al que se ofrece. Sobre esta cuestión, vid. CAPEL, H., Capitalismo y morfología urbana en España, Amelia Romero, Barcelona, 1983, p. 20, que subraya el problema en una fecha tan temprana como principios de la década de los ochenta.

${ }^{44}$ Efectivamente, los Estados se pliegan a las exigencias de los mercados financieros, lo que da lugar a políticas desreguladoras más allá de las preferencias de los electores. Vid., en este sentido, STIGLITZ, J., The Price of Inequality, Norton, Nueva York, Londres, 2013, p. 174. En el caso español, con un Estado social en ciernes, esta situación es particularmente intensa, como pone de manifiesto la reforma en 2011 del artículo 135 CE.

${ }^{45}$ En este contexto, la apelación del marco constitucional al desarrollo sostenible constituye una estrategia retórica legitimadora de las estructuras hegemónicas de reproducción social. Baste constatar aquí el ejemplo más cercano, que es el de la Unión Europea. Así, el artículo 3.3 TUE establece: "La Unión [... o]brará en pro del desarrollo sostenible de Europa basado en un crecimiento económico equilibrado y en la estabilidad de los precios, en una economía social de mercado altamente competitiva, tendente al pleno empleo y al progreso social, y en
} 
del sistema continúan reposando en su capacidad de crear bienestar entendido fundamentalmente como disponibilidad social de bienes y servicios, las estrategias y los discursos legitimadores evolucionan, poniendo el énfasis en el crecimiento económico a través de la capacidad del sistema de generar inversión privada mediante la desregulación y la privatización, y ya no tanto mediante la capacidad de intervención del Estado como actor redistribuidor de recursos y generador de actividad económica ${ }^{46}$.

Con ello, el Estado social deviene frágil ante la presión de los mercados internacionales de capital sobre las políticas públicas internas y el aparato normativo que representa la supraconstitución del capitalismo global ${ }^{47}$. En este contexto, la actividad limitativa del legislador democrático en defensa de determinados bienes constitucionales de carácter colectivo o de determinados derechos cuyo ejercicio efectivo viene condicionado por la disponibilidad o accesibilidad de ciertos bienes o servicios se erosiona significativamente, lo que incide en la capacidad del Estado-nación de seguir siendo el elemento de

un nivel elevado de protección y mejora de la calidad del medio ambiente". Ello es coherente con el sistema constitucional español, del que puede derivarse, asimismo, una vocación hacia el desarrollo sostenible. Así lo he defendido, de acuerdo con una interpretación sistemática de los artículos 40, 45 y $130 \mathrm{CE}$, en El sistema constitucional... cit., p. 153 y ss. El proceso de retirada del sector público se proyecta en las dos facetas del Estado social, tanto en su participación en la prestación de servicios — privatización; particularmente intensa durante los años noventa- como en su faceta reguladora. Con ello, se va produciendo un desequilibrio en favor de la libertad de empresa, que, por otro lado, se refuerza con la evolución del derecho de la Unión Europea. Todo ello escora el sistema constitucional hacia una sobreprotección de las libertades económicas con el objetivo de generar un crecimiento económico que proporcione un marco de bienestar razonablemente aceptable. Este es el marco conceptual en el que se despliega la jurisprudencia constitucional que se analiza a continuación

${ }^{46}$ Vid. JARIA I MANZANO, "La externalización..." cit., p. 30 y ss. Por otro lado, el marco internacional, favorable al levantamiento de barreras comerciales (OMC), la competencia en la atracción de capitales y la desregulación financiera, ha condicionado los equilibrios del sistema constitucional en relación con la tensión tradicional entre libertad económica y tutela de los bienes comunes y de los derechos sociales. Vid. CLARKSON y WOOD, A Perilous Imbalance... cit., p. 161 y ss. Todo ello, efectivamente, conduce hacia un reforzamiento de ciertos elementos del modelo económico constitucional —particularmente, las libertades económicas, esto es, los artículos 33 y $38 \mathrm{CE}$, pero también el progreso social y económico (art. 40.1 CE), la modernización y desarrollo de todos los sectores económicos (art. 130.1 CE) o el crecimiento de la renta y de la riqueza (art. 131.1 CE) — en detrimento de otros, como la protección del medio ambiente.

47 Vid. LAPORTA, F. J., "Globalización e imperio de la ley. Algunas dudas westfalianas", CARBONELL, M. y VÁZQUEZ, R. (eds.), Globalización y Derecho, Ministerio de Justicia y Derechos Humanos, Quito, 2009, p. 213 y ss. En definitiva, se produce una ruptura entre espacio de reproducción social —el mercado global- y espacio de visualización del poder —el Estado-nación-, con el correspondiente déficit en la fiscalización del poder y la exigencia de responsabilidades. Vid., en este sentido, MUCHLINSKI, P., "Corporations in International Litigation: Problems of Jurisdiction and the United Kingdom Asbestos Cases", International Comparative Law Quarterly, vol. 50, 2001, p. 1. 
referencia desde el punto de vista de la garantía del estatus de ciudadanía ${ }^{48}$. Por otro lado, la necesidad de obtener financiación para la prestación de tales servicios implica una presión suplementaria sobre el medio ambiente, cuya protección queda en entredicho ante el doble fenómeno de la erosión del Estado social y de las necesidades de financiación de lo que queda de él ${ }^{49}$.

La estructura económica española, con la importancia crucial que asumen sectores como la construcción, el turismo y la energía, conlleva que, finalmente, los beneficiarios de tal espacio de libertad, generado por un marco legislativo que promueve la progresiva retirada del sector público y el estímulo de la actividad empresarial privada, sean, en muchos casos, actores particularmente intensivos en el uso y explotación de los recursos naturales. De todo ello se deriva que, en el momento actual, el énfasis constitucional debe ponerse ya no tanto en la justificación de la intervención pública reguladora, sino en el control de la intervención pública desreguladora o facilitadora del acceso de los actores económicos a los recursos naturales ${ }^{50}$. Veamos, efectivamente, cómo se ha desarrollado la actividad normativa en el contexto de la crisis.

\section{ACTIVIDAD NORMATIVA PÚBLICA Y CAPTURA DEL LEGISLADOR: LA QUIEBRA DEL MODELO ECONÓMICO CONSTITUCIONAL EN TIEMPOS DE CRISIS}

\footnotetext{
${ }^{48}$ Sobre el papel de los Estados contemporáneos como espacios democráticos y garantes de los derechos, vid. THÜRER, D., "Recht der internationalen Gemeinschaft und Wandel der Staatlichkeit”, THÜRER, D., AUBERT, J.-F. y MÜLLER, J. P. (eds.), Verfassungsrecht der Schweiz / Droit constitutionnel suisse, Schulthess, Zúrich, 2001, p. 55.

${ }^{49}$ Debe recordarse aquí que los beneficiarios de estas políticas que tienden a debilitar el Estado social y a desproteger el medio ambiente son las grandes estructuras empresariales, que, al mismo tiempo, condicionan el funcionamiento de los mercados internacionales de capital, que, en este contexto, devienen ámbitos en los que dichas compañías transnacionales pueden condicionar las políticas de los Estados, con la consiguiente quiebra de la lógica democrática y del mismo principio de constitucionalidad. Vid. WESTAWAY, J., "Globalization, Transnational Corporations and Human Rights - A New Paradigm", International Law Research, vol. 1, núm. 1, 2012, p. 63.

${ }^{50}$ Así, la constitución deviene más bien el fundamento del control del poder político, en ocasiones sometido a la captura por parte de los actores económicos interesados, que no un núcleo de irradiación normativa, imponiéndose la centralidad de la aplicación y la interpretación del derecho sobre su producción. Vid. ZAGREBELSKY, El derecho dúctil... cit., p. 14.
} 
El Estado social es un constructo desarrollista ${ }^{51}$. Respondiendo a la pulsión por el progreso y a la generalización del ethos burgués que acaban propugnando tanto el socialismo como la socialdemocracia, el Estado social promueve la explotación intensiva de los recursos naturales para proporcionar los fundamentos materiales asociados al disfrute de un bienestar material suficiente, de acuerdo con la idea del constitucionalismo existencial, concentrado en la situación real de los ciudadanos y no tanto en su estatuto formal $^{52}$. En principio, la protección del medio ambiente tiene un carácter ancilar en relación con la preservación de unas condiciones de vida apropiadas para el despliegue de la dignidad de la persona ${ }^{53}$. Sin embargo, en tiempos recientes se ha operado un cambio de estrategia en el establecimiento de mínimos de bienestar, en el contexto de la dependencia financiera de los Estados en la fase actual de despliegue del proceso de acumulación capitalista, que, en cualquier caso, exige siempre más crecimiento para lograr saldar las deudas y proporcionar los servicios requeridos por la comunidad ${ }^{54}$. En este sentido, el discurso de la creación de empleo a partir del crecimiento del PIB sustituye los elementos redistribuidores de la acción económica del Estado.

\footnotetext{
${ }^{51}$ Vid. BAUDRILLARD, J., La sociedad de consumo. Sus mitos, sus estructuras, Siglo XXI, Madrid, 2009 (traducción de Alicia Bixio con estudio preliminar de Luis Enrique Alonso), p. 39 y ss., para la continuidad entre el liberalismo originario y el Estado social, así como sus implicaciones desde el punto de vista de la promoción del consumo y, con ello, del crecimiento económico y de los postulados desarrollistas.

${ }^{52}$ Sobre la continuidad del ethos burgués en el socialismo, así como la persistencia de la confianza en el progreso y la idea de dominación sobre la naturaleza, vid. BUCK-MORSS, S., Origen de la dialéctica negativa. Theodor W. Adorno, Walter Benjamin y el Instituto de Frankfurt, Siglo XXI, México, Madrid, Buenos Aires, Bogotá, 1981 (versión castellana de Nora Rabotnikof Maskivker), pp. 137-138; y JONAS, H., El principio de responsabilidad. Ensayo de una ética para la civilización tecnológica, Herder, Barcelona, 1995 (versión castellana de José María Fernández Retenaga), p. 236.

${ }^{53}$ Sobre el vínculo entre la protección del medio ambiente y la dignidad de la persona, vid., por todos, CANOSA USERA, R., Constitución y medio ambiente, Dykinson, Madrid, 2000, p. 26.

${ }^{54}$ Ante la apertura de la Constitución en relación con los instrumentos adecuados para avanzar en la plenitud del disfrute de la condición humana y el diseño del propio proyecto de vida (arts. 9.2 y $10.1 \mathrm{CE}$ ), que constituyen su núcleo ético fundamental, los poderes públicos se adaptan a la situación generada por un marco internacional que promueve el desarrollo y la apertura económicos, lo que, en última instancia, redunda en la desprotección del medio ambiente. Todo ello se admite en el contexto de la apertura de la Constitución, que deja un margen amplio al legislador, particularmente en las materias relativas a la cláusula de Estado social. Así, el Tribunal Constitucional ha insistido en este carácter abierto, de modo que sea posible la persecución de diferentes programas políticos resultantes de las mayorías parlamentarias que surgen de las sucesivas convocatorias electorales. En definitiva, de acuerdo con el juez de la constitucionalidad, "la función de legislar no puede entenderse como una simple ejecución de los preceptos constitucionales" (STC 227/1988, de 29 de noviembre, FJ 7. ${ }^{\circ}$ ).
} 
Pues bien, ante el carácter abierto que presenta la configuración constitucional del medio ambiente protegido, el legislador democrático emprende una caracterización infraconstitucional regresiva que se ampara en la "utilización racional de los recursos naturales" (art. 45.2 CE) para satisfacer las necesidades sociales, de acuerdo con una concepción del bienestar humano que se despliega desde la dignidad de la persona (art. 10.1 CE) en una serie de derechos y principios que definen el horizonte teleológico de los poderes públicos, admitiendo, como se ha dicho, la pluralidad de enfoques en los instrumentos y un cierto margen de apreciación en los fines ${ }^{55}$.

En este contexto abierto, el legislador debe definir primariamente el medio ambiente protegido teniendo en cuenta la pluralidad de derechos, bienes jurídicos e intereses jurídicamente protegidos que vienen a confluir en él, así como los condicionantes externos que determinan el alcance material de las regulaciones acordadas en sede parlamentaria o administrativa ${ }^{56}$. Ahora bien, en la última década, cabe señalar que ha primado, de forma desproporcionada, el componente desarrollista en el despliegue de una legislación de contenido económico destinada, en buena parte, a facilitar el acceso a los recursos naturales, tanto en las Cortes Generales como en las diferentes asambleas legislativas de las comunidades autónomas ${ }^{57}$. La situación de grave crisis

\footnotetext{
${ }^{55}$ Todo ello se corresponde con la idea de constitución abierta de Konrad Hesse, que la defiende en distintas obras, como, por ejemplo, en "Concepto y cualidad de la Constitución", Escritos de Derecho Constitucional, Centro de Estudios Constitucionales, Madrid, 1992 (edición castellana de Pedro Cruz Villalón), pp. 1-29. Para una concepción análoga a la de Hesse en la literatura constitucionalista española, vid. VERNET I LLOBET, J., "La apertura del sistema autonómico", Anuario de Derecho Constitucional y Parlamentario, núm. 14, 2002, p. 127 y ss.

${ }^{56}$ En cuanto a la necesidad de la intermediación legislativa en relación con el establecimiento del régimen jurídico de los derechos sociales, vid. FERNÁNDEZ RODRíGUEZ, J. J., La inconstitucionalidad por omisión. Teoría general. Derecho comparado. El caso español, Civitas, Madrid, 1998, p. 192. Aunque es dudoso que el derecho al medio ambiente pueda calificarse como un derecho social, en cualquier caso, es evidente, de manera particularmente intensa, la necesidad de la intermediación legislativa en este caso, dado el complejo de intereses que confluyen en la articulación jurídica del objeto del derecho. En este sentido, el Tribunal Constitucional ha señalado que "es el legislador quien ha de determinar las técnicas apropiadas para llevar a cabo la plasmación de ese principio rector en el que la protección del medio ambiente consiste" (STC 149/2011, de 28 de septiembre, FJ 3..$^{\circ}$.

${ }^{57}$ Entre las medidas más claras en este sentido, cabe apuntar la modificación de la legislación de costas mediante la Ley $2 / 2013$, de 29 de mayo, de protección y uso sostenible del litoral y de modificación de la Ley 22/1988, de 28 de julio, de Costas. En este caso, se ve claramente la opción por facilitar el acceso a los recursos del sector de la construcción, intensivo en el uso de la fuerza de trabajo, mediante la externalización de los costes ambientales. En el mismo plano de actuación, cabe mencionar como particularmente significativa la Ley de Cantabria 4/2013,
} 
económica que se prolonga desde 2007 ha justificado una serie de medidas dirigidas a captar inversiones y a recuperar el crecimiento económico, a costa de rebajar hasta extremos inauditos los niveles de protección ambiental ${ }^{58}$.

El programa desarrollista con el que se ha encarado la crisis económica ha derivado en una serie de decisiones legislativas cuyo objetivo es sostener democráticamente la disponibilidad, cuando menos discutible, de los recursos naturales ante oportunidades de inversión que deben proporcionar puestos de trabajo, cumpliendo así, aparentemente, con el programa constitucional de bienestar en el marco de un contexto económico desfavorable a los elementos regulativos de origen democrático, así como ante la existencia de un progresivo deslizamiento del sistema constitucional global hacia la creación de espacios de libertad para los grandes operadores privados o, incluso, mecanismos de redistribución dirigidos a preservar su posición en el mercado, siempre dentro del paradigma del desarrollo sostenible ${ }^{59}$.

de 20 de junio, relativa al régimen jurídico de las autorizaciones provisionales de edificaciones o actuaciones preexistentes.

${ }^{58}$ En este sentido, vid. "Editorial: Involución ambiental y respuesta constitucional", Revista Catalana de Dret Ambiental, vol. 4, núm. 1, 2013.

${ }^{59}$ Cabe mencionar aquí, como ejemplo particularmente relevante de este tipo de medidas, la aprobación de leyes singulares destinadas a satisfacer las demandas de los inversores para llevar a cabo determinados proyectos, presuntamente susceptibles de crear puestos de trabajo $y$, en cualquier caso, de impacto mediático evidente - con el interés político consecuente por parte de los Gobiernos que los promueven-. Así, cabe referirse a la llamada "cláusula Eurovegas", introducida en la legislación de la Comunidad de Madrid a través de la Ley 4/2012, de 4 de julio, de Modificación de la Ley de Presupuestos Generales de la Comunidad de Madrid para el año 2012, y de medidas urgentes de racionalización del gasto público e impulso y agilización de la actividad económica, que en su artículo 22 procedía a una modificación de la Ley 9/1995, de 28 de marzo, de medidas de política territorial, suelo y urbanismo, que permitía la conversión de suelo no urbanizable en urbanizable en las llamadas zonas de interés regional. En este caso, como en otros muchos, el legislador, en definitiva, se comprometía con una política de generación de medidas de estímulo económico que optaba por el sacrificio del medio ambiente ante la necesidad de recuperar el crecimiento, en un contexto de economía claramente orientada hacia la especulación. También debe mencionarse la Ley castellanoleonesa 6/2010, de 28 de mayo, de declaración de Proyecto Regional del "Complejo de Ocio y Aventura Meseta-Ski”, que creaba un régimen jurídico específico para el mencionado proyecto. En este caso, sin embargo, el Tribunal Constitucional, si bien concentrándose en la tutela de las competencias estatales más que en otra cosa, declaró la inconstitucionalidad de la Ley en la STC 162/2014, de 7 de octubre de 2014. Finalmente, sin ánimo de exhaustividad y como muestra del fenómeno, aunque la derogación específica no tenía relevancia ambiental manifiesta, debe recordarse también la Ley catalana 6/2014, de 10 de junio, de modificación de la Ley $2 / 1989$, de 16 de febrero, sobre centros recreativos turísticos, y de establecimiento de normas en materia de tributación, comercio y juego, que introducía un trato especial para el complejo BCN World. 
Debe señalarse, en este punto, que las exigencias de los mercados internacionales de capital han derivado en políticas monetarias estrictas, dirigidas a combatir la inflación y el déficit público con el objeto de evitar el aumento de la prima de riesgo y poder acceder a la financiación en unas condiciones más o menos asumibles ${ }^{60}$. Este es el contexto para la combinación entre una legislación que ofrece un trato privilegiado a los actores y la dependencia de los poderes públicos del acceso a los mercados para alcanzar la legitimación que, antaño, obtenían a través de los instrumentos propios del Estado social. Por este motivo, podemos hablar de una captura del regulador generalizada ${ }^{61}$.

\section{RECENTRALIZACIÓN, NEODESARROLLISMO Y JUSTICIA CONSTITUCIONAL}

Establecida la primacía del legislador en la configuración del medio ambiente protegido, así como la deriva regresiva, que se ha agravado en el contexto de la crisis económica, cabe preguntarse si hay límites en relación con la ponderación de los bienes jurídicos en presencia. A mi juicio, ciertamente debe de haberlos, en la medida en que la Constitución formal define el consenso social básico en el ámbito estatal, configurándose como un límite para el ejercicio del poder $^{62}$. Así, si bien la libertad del legislador para desarrollar su programa legislativo en el marco constitucional en relación con la protección del medio ambiente es amplia, no es absoluta, de modo que no cabe cualquier ponderación, aun reconociendo su complejidad, en la configuración jurídica del metabolismo social y, en particular, en relación con la disponibilidad de los

\footnotetext{
${ }^{60}$ Vid. HELD, MCGREW, GOLDBLATT y PERRATON, Global Transformations... cit., p. 229.

${ }^{61}$ Sobre el concepto de regulatory capture, en el que operan fenómenos menos globales que la estructura de financiación del Estado, como es el caso de las puertas giratorias o la corrupción, vid. DAL BÓ, E., "Regulatory Capture: A Review", Oxford Review of Economic Policy, vol. 22, núm. 2, 2006, pp. 203-225.

${ }^{62}$ Vid., en este sentido, BALAGUER CALLEJÓN, F., "Derechos fundamentales y Constitución normativa", VV. AA., Introducción a los derechos fundamentales (I), Ministerio de Justicia, Madrid, 1988, p. 212. En definitiva, el Estado constitucional de derecho se caracterizaría por sometimiento del legislador a la Constitución a través del control de constitucionalidad. Este argumento lo desarrolla Manuel García-Pelayo en su trabajo "El 'status' del Tribunal Constitucional”, Revista Española de Derecho Constitucional, núm. 1, 1981, pp. 18-19. Otra cosa es la prudencia del juez de la constitucionalidad a la hora de administrar sus atribuciones en el contexto de una constitución abierta.
} 
recursos naturales para posibilitar el desarrollo económico que la Constitución propugna $^{63}$.

Llegados a este punto, se impone, a nuestro juicio, el desplazamiento del énfasis en relación con la función constitucional del artículo $45 \mathrm{CE}$ desde su condición de habilitación para el legislador a su condición de parámetro de control de este $-\mathrm{y}$ de los poderes públicos en general ${ }^{64}$. Sin embargo, ha sucedido que, en aspectos cruciales para definir el grado de protección del medio ambiente en el sistema y, en consecuencia, la proyección del artículo 45 CE sobre el legislador, el Tribunal Constitucional, en lugar de reaccionar ante el proceso de regresión en esta materia, ha tendido más bien a bloquear ciertas iniciativas tuitivas o a amparar las decisiones legislativas encuadradas en el proceso de retroceso descrito.

Hay que empezar por subrayar que la gran mayoría de las cuestiones ambientales resueltas por el Tribunal Constitucional se refieren a aspectos relativos a la distribución de competencias en el contexto del Estado autonómico. Esto ha sido así históricamente y también sirve para el período posterior al estallido de la crisis de $2007^{65}$. En cualquier caso, cabe señalar, en primer lugar, que las tendencias apuntadas de la jurisprudencia constitucional en relación con la respuesta legislativa a la crisis económica no se aprecian en el primer tramo del período, entre 2007 y 2013, ya que el Tribunal Constitucional aún está resolviendo contenciosos previos a 2007, entre los cuales destacan las cuestiones relativas a la política de aguas, en el contexto de la conflictividad generada por el Plan Hidrológico Nacional ${ }^{66}$.

\footnotetext{
${ }^{63}$ Así lo señala Nicolai MÜLLER-BROMLEY en Staatszielbestimmung Umweltschutz im Grundgesetz? Rechtsfragen der Staatszielbestimmung als Regelungsform der Staatsaufgabe Umweltschutz, Eric Schmidt, Berlín, 1990, p. 117.

${ }^{64}$ Vid. RUIZ ROBLEDO, A., "Un componente especial de la Constitución económica: La protección del medio ambiente", Revista Andaluza de Administración Pública, núm. 14, 1993, p. 35.

${ }^{65}$ En relación con la evolución previa de la jurisprudencia constitucional en este ámbito, vid. JARIA I MANZANO, J., "Problemas competenciales fundamentales en materia de protección del medio ambiente", Revista Vasca de Administración Pública, núm. 73 (I), 2005, pp. 117-134.

${ }^{66}$ Hay que destacar aquí las SSTC 30/2011, de 16 de marzo; 32/2011, de 17 de marzo; 110/2011, de 22 de junio; 149/2011, de 28 de septiembre; 149/2012, de 5 de julio (parcialmente referida a aguas); 195/2012, de 31 de octubre; 237/2012, de 13 de diciembre; 239/2012, de 13 de diciembre; 240/2012, de 13 de diciembre; 19/2013, de 31 de enero; 36/2013, de 14 de febrero; 51/2013, de 28 de febrero; y 64/2013, de 14 de marzo. Posteriormente, aún cabe mencionar la STC 13/2015, de 5 de febrero. Asimismo, también debe señalarse la existencia
} 
A partir de 2013, sin embargo, puede constatarse una tendencia clara que aúna recentralización y regresión ambiental en una jurisprudencia que viene a salvar buena parte de las controvertidas decisiones de las instituciones centrales del Estado relacionadas con la protección del medio ambiente, al mismo tiempo que bloquea la reacción autonómica ante ellas. El ámbito de la energía es particularmente significativo en esta cuestión, como muestra la conflictividad suscitada en cuestiones como la fractura hidráulica o las energías renovables. Efectivamente, la problemática energética habría sustituido al debate hidráulico en los últimos años como cuestión central en la jurisprudencia constitucional en materia de protección del medio ambiente ${ }^{67}$.

\section{El debate constitucional sobre la fractura hidráulica}

La fractura hidráulica ha dado lugar a una notable actividad legislativa por parte de ciertas comunidades autónomas que ha generado la oposición del Estado y los correspondientes pronunciamientos del Tribunal Constitucional. La primera de las decisiones del Alto Tribunal en este ámbito es la STC 106/2014, de 24 de junio, que se pronunciaba en relación con el recurso de inconstitucionalidad interpuesto por el Presidente del Gobierno contra la Ley del Parlamento de Cantabria 1/2013, de 15 de abril, por la que se regula la prohibición en el territorio de la Comunidad Autónoma de Cantabria de la fractura hidráulica como técnica de investigación y extracción de gas no convencional. En la línea de avalar las políticas regresivas en materia ambiental, es muy significativo constatar que, en la mencionada decisión, el Tribunal Constitucional renuncia a hacer consideraciones sustantivas y, en consecuencia, a utilizar el artículo 45 CE como parámetro de constitucionalidad, ya que considera que "[n]o corresponde a este Tribunal tomar postura sobre tema de tan debatido alcance, sino únicamente dictaminar si la Ley impugnada ha incurrido o no en

de una significativa conflictividad suscitada por la Ley 42/2007, de 13 de diciembre, del Patrimonio Natural y de la Biodiversidad, que dio lugar a las SSTC 69/2013, de 14 de marzo; 87/2013, de 11 de abril; y 138/2013, de 6 de junio.

${ }^{67}$ Vid. JARIA I MANZANO, J., "Jurisprudencia constitucional en materia de protección del medio ambiente (Segundo semestre 2014)", Revista Catalana de Dret Ambiental, vol. 5, núm. 2, 2014, p. 9. 
inconstitucionalidad, por extralimitación —alegada por el Gobierno- de sus competencias en la materia" ${ }^{\circ 8}$.

Por otro lado, desde el punto de vista competencial, el juez de la constitucionalidad prioriza la norma estatal, de contenido manifiestamente extractivista, en detrimento de la norma autonómica, mayormente tuitiva en relación con el medio ambiente. Así, el Tribunal Constitucional considera que la Ley 17/2013, de 29 de octubre, para la garantía del suministro e incremento de la competencia en los sistemas eléctricos insulares y extrapeninsulares, tiene carácter básico $\mathrm{y}$, en la medida que no prohíbe la fractura hidráulica, la prohibición autonómica deviene inconstitucional ${ }^{69}$. Es muy significativo que, a la hora de articular su argumentación, el juez de la constitucionalidad no tenga en cuenta ni el carácter sobrevenido de las bases en este caso ni la posible condición de norma adicional de protección de la prohibición del fracking, optando por una interpretación sesgada de la noción de desarrollo sostenible ${ }^{70}$.

\footnotetext{
${ }^{68}$ Vid. STC 106/2014, de 24 de junio, FJ 3. ${ }^{\circ}$.

${ }^{69}$ Vid. FJ 6. ${ }^{\circ}$.

${ }^{70}$ Así, en el FJ 8. ${ }^{\circ}$ el Tribunal considera:
}

\begin{abstract}
Este Tribunal afirmó en la citada STC 64/1982, de 4 de noviembre, la "necesidad de compaginar en la forma que en cada caso decida el legislador competente la protección de ambos bienes constitucionales: el medio ambiente [art. $45 \mathrm{CE}$ ] y el desarrollo económico [art. 130.1 CE]" (STC 64/1982, FJ 2); asimismo, que el art. 128.1 CE "supone que no pueden substraerse a la riqueza del país recursos económicos que el Estado considera de interés general, aduciendo otras finalidades como la protección del medio ambiente. Se trata de nuevo de armonizar la protección del medio ambiente con la explotación de los recursos económicos. Ello supone que, si bien la imposición de una carga adicional para la protección del medio ambiente no es en sí contraria a la Constitución ni al Estatuto, sí lo es la prohibición con carácter general de las actividades extractivas [...] de mayor importancia económica [...]. Cuestión distinta es que puedan prohibir la actividad minera en casos concretos, siempre que no exista un interés prioritario, pero el carácter general con la excepción citada, que prevé [...] la Ley impugnada, debe tacharse de inconstitucional [...] por substraer a la riqueza nacional posibles recursos mineros" (STC 64/1982, FJ 6). Esta doctrina se reitera, entre otras, en las SSTC 170/1989, de 19 de octubre, FJ 7, y 102/1995, de 26 de junio, FJ 4.
\end{abstract}

Esta jurisprudencia se reitera en la STC 134/2014, de 22 de julio, que resolvía el recurso de inconstitucionalidad interpuesto por el Presidente del Gobierno respecto de la Ley del Parlamento de La Rioja $7 / 2013$, por la que se regula la prohibición en el territorio de la Comunidad Autónoma de La Rioja de la fractura hidráulica como técnica de investigación y extracción de gas no convencional, y, posteriormente, en la STC 208/2014, de 15 de diciembre, relativa al recurso de inconstitucionalidad promovido por el Presidente del Gobierno en relación con los artículos 1,2 y 3 , la disposición transitoria única y la disposición final única de la Ley Foral 30/2013, de 15 de octubre, del Parlamento de Navarra, por la que se prohíbe en el territorio de la Comunidad Foral de Navarra el uso de la fractura hidráulica como técnica de investigación y extracción de gas no convencional. Esta línea jurisprudencial se ha prolongado 
Como señala el voto particular a la Sentencia, en definitiva, esta "no pondera debidamente la incidencia de los riesgos del fracking en un interés de la máxima relevancia constitucional como es la protección de la salud humana", esto es, ignora las consideraciones sustantivas imprescindibles en el contexto de la ponderación de intereses que confluyen en la configuración del medio ambiente protegido ${ }^{71}$.

\section{La política energética y las energías renovables}

El cambio de orientación dramático de la política energética en España en el último lustro ha provocado una notable conflictividad competencial, a la que me voy a referir seguidamente ${ }^{72}$. Empiezo por mencionar la STC 96/2014, de 12 de junio, en la que se resolvía el recurso de inconstitucionalidad presentado por el Consejo de Gobierno de la Región de Murcia en relación con el Real DecretoLey 14/2010, de 23 de diciembre, por el que se establecen medidas urgentes para la corrección del déficit tarifario del sector eléctrico, que modificaba muy

en la STC 260/2015, de 3 de diciembre, sobre el recurso de inconstitucionalidad interpuesto contra la Ley 10/2014, de 1 de octubre, de ordenación minera de las Illes Balears. Nuevamente, en este caso, el Tribunal Constitucional se desvincula de las consideraciones ecosistémicas necesarias en cualquier política ambiental razonable, sosteniendo una fragmentación competencial que acaba favoreciendo las opciones desarrollistas de escasa sensibilidad ambiental.

${ }^{71}$ Vid. el voto particular suscrito por los magistrados Valdés Dal-Ré, Xiol Ríos y Asua Batarrita.

${ }^{72}$ Cabe notar, por lo demás, que se trata de un cambio muy discutible en el contexto de un marco jurídico supraconstitucional, en el sentido que he utilizado este término. En este sentido, debe mencionarse que la Carta Europea de la Energía promueve un marco jurídico estable y transparente para las inversiones extranjeras, circunstancia reconocida por el propio Tribunal Constitucional, sin efecto práctico alguno, por otro lado, al afirmar "la necesidad de dotar de seguridad y permanencia a las inversiones en energías renovables y la prohibición de adoptar medidas que afecten a dichas inversiones con efectos equivalentes a la expropiación" (STC 270/2015, de 17 de diciembre, FJ 6. ${ }^{\circ}$ ). En relación con esta cuestión, el magistrado Juan Antonio Xiol Ríos, en el voto particular a la Sentencia al que se adhieren los magistrados Adela Asua Batarrita y Fernando Valdés Dal-Ré, señala que "la existencia de litigios en que se reclama el pago por el Reino de España de cuantiosas indemnizaciones a los inversores extranjeros derivadas de las sucesivas modificaciones normativas - a pesar del parcialmente diferente significado que puede asumir el principio de confianza legítima dentro del Derecho internacional económico y de las inversiones, aplicable por las diferentes cortes internacionales de arbitraje, respecto del que asume su consagración como principio en la Constitución española, que es el aplicable en el marco del presente recurso de inconstitucionalidad- hacía a mi juicio deseable que este Tribunal Constitucional, como un órgano más conformador del entramado institucional del Reino de España, aunque no considere, como así es, no infringido el expresado principio, hubiera aportado un estudio más amplio y reflexivo sobre la cuestión, asumiendo también la responsabilidad, como ya hiciera el Tribunal Supremo, de desentrañar las particularidades del ordenamiento jurídico español en relación con la materia". 
significativamente el régimen retributivo previsto en el Real Decreto 661/2007 ${ }^{73}$. Esta es la primera de las distintas sentencias que se han producido en relación con la reorientación reciente de la política energética en España, que ha transitado, impasiblemente, del incentivo al desincentivo del uso de energías renovables, en contradicción con todo el marco internacional relativo a la mitigación y adaptación al cambio climático ${ }^{74}$.

En la medida en que la norma impugnada ya no estaba en vigor en el momento de la decisión, el Tribunal Constitucional se limita a pronunciarse sobre la existencia del presupuesto habilitante del Decreto-Ley, de acuerdo con su jurisprudencia anterior ${ }^{75}$. Sin embargo, no entra en el fondo del asunto, ya que la norma controvertida había sido derogada, con lo que el juez de la constitucionalidad "entra en una pendiente peligrosa, en la medida en que, atendiendo a su lentitud en resolver y la volatilidad de las normativas reguladoras en sectores penetrados por el conocimiento experto y la utilización sistemática de la ley-medida, virtualmente elimina el control de constitucionalidad en campos como el sector energético o el sector financiero"76. Se abre, pues, un espacio opaco al control de constitucionalidad

\footnotetext{
${ }^{73}$ En concreto, se establecía un peaje de acceso a las redes de transporte y distribución para los productores de energía eléctrica, así como la vinculación de la percepción del régimen económico primado al número de horas equivalentes, que se establecerían en función de las zonas climáticas según la radiación media solar en España, reguladas en el Real Decreto 314/2006, de 17 de marzo, por el que se aprueba el Código Técnico de la Edificación. En cualquier caso, la norma impugnada había sido modificada en el momento del pronunciamiento del Alto Tribunal por la disposición final cuadragésimo cuarta, apartado 2, de la Ley 2/2011, de 4 de marzo. La STC 109/2014, de 26 de junio, resolvía, en los mismos términos, el recurso de inconstitucionalidad interpuesto por el Consejo de Gobierno de la Generalitat Valenciana. También, en relación con la validación del presupuesto habilitante en materia energética, vid. la STC 270/2015, de 17 de diciembre. Asimismo, en relación con esta cuestión, vid., en el mismo sentido, las SSTC 19/2016, de 4 de febrero; 29/2016, de 18 de febrero; 30/2016, de 18 de febrero; y 42/2016, de 3 de marzo.

${ }^{74}$ Sin ir más lejos, el artículo 4.1 del Acuerdo de París de 2015 señala lo siguiente:

Para cumplir el objetivo a largo plazo referente a la temperatura que se establece en el artículo 2, las Partes se proponen lograr que las emisiones mundiales de gases de efecto invernadero alcancen su punto máximo lo antes posible, teniendo presente que las Partes que son países en desarrollo tardarán más en lograrlo, y a partir de ese momento reducir rápidamente las emisiones de gases de efecto invernadero, de conformidad con la mejor información científica disponible, para alcanzar un equilibrio entre las emisiones antropógenas por las fuentes y la absorción antropógena por los sumideros en la segunda mitad del siglo, sobre la base de la equidad y en el contexto del desarrollo sostenible y de los esfuerzos por erradicar la pobreza.

${ }^{75}$ Así, la STC 155/2005, de 9 de junio, FJ 2..

${ }^{76}$ Vid. JARIA I MANZANO, “Jurisprudencia constitucional en materia de..." cit., p. 12.
} 
que, obviamente, favorece los procesos de captura del regulador que puedan producirse en sectores sensibles.

En relación con la cuestión sobre la que el Tribunal Constitucional entra a decidir, esto es, la existencia del presupuesto habilitante, considera que "puede concluirse que la situación de urgencia aparece expresamente justificada en el preámbulo del Real Decreto-ley así como en el debate parlamentario de convalidación del mismo. En ambos casos coinciden las razones que motivaron la adopción de la medida, que son por un lado la situación de crisis económica en 2010, que había repercutido en una caída imprevista de la demanda de energía eléctrica, junto al incremento general de costes, que provocó un aumento imprevisto del déficit tarifario. De otro lado la existencia de un régimen retributivo especial, que no se fijó mediante el precio de mercado, sino que tiene como finalidad garantizar una rentabilidad suficiente, que tuvo también una cierta incidencia en déficit tarifario"77. En definitiva, de acuerdo con el Tribunal Constitucional, la legislación de urgencia en tiempos de crisis en sectores de elevada complejidad técnica y significativa volatilidad normativa parece quedar más allá del control de constitucionalidad ${ }^{78}$.

\footnotetext{
${ }^{77}$ Vid. STC 96/2014, de 12 de junio, FJ 5.․

${ }^{78}$ Posteriormente, el Tribunal Constitucional ha desplegado una jurisprudencia del mismo tenor en relación con el Real Decreto-Ley 1/2012, de 27 de enero, por el que se procede a la suspensión de los procedimientos de preasignación de retribución y a la supresión de los incentivos económicos para nuevas instalaciones de producción de energía eléctrica a partir de cogeneración, fuentes de energía renovables y residuos. En este caso, resuelto por la STC 48/2015, de 5 de marzo, el Tribunal Constitucional considera que "el Real Decreto-ley minimiza el riesgo de eventuales desviaciones al alza del déficit, lo que, como dijimos en la STC 183/2014, constituye una situación susceptible de ser abordada mediante la legislación de urgencia, constatándose una evidente conexión entre la situación de extraordinaria y urgente necesidad y las medidas adoptadas para hacerle frente" (FJ $3^{\circ}{ }^{\circ}$. Sin embargo, como señala el voto particular del magistrado Valdés Dal-Ré, "[l]a situación del sistema eléctrico, la compleja situación económica y financiera y la lucha contra el déficit tarifario son motivos que narran el contenido de la adopción de la disposición; pero ni justifican la aprobación mediante la promulgación del Real Decreto-ley impugnado, ni explican la razón que llevó al Gobierno a tramitar la suspensión del régimen primado de producción de energía eléctrica por medio de esa norma excepcional y no de una ley, excepto en el caso de las instalaciones de producción fotovoltaica". En cualquier caso, el Tribunal Constitucional ha mantenido su línea jurisprudencial en las posteriores SSTC 105/2015, de 28 de mayo, y 106/2015, de 28 de mayo. Debe mencionarse, finalmente, la reciente STC 205/2016, de 1 de diciembre (BOE, núm. 7, de 9 de enero de 2017), que resolvía positivamente el recurso de inconstitucionalidad interpuesto por el Presidente del Gobierno respecto del apartado 12 del artículo único de la Ley de la Asamblea Regional de Murcia 11/2015, de 30 de marzo, de modificación de la Ley 10/2006, de 21 de diciembre, de energías renovables y ahorro y eficiencia energética de la Región de Murcia. En este caso, la cuestión controvertida era el pago del peaje de red por parte de instalaciones de autoconsumo. El Tribunal Constitucional realiza una interpretación extensiva de la legislación básica para anular la norma autonómica que permitía excepciones al régimen
} 
Dentro de este panorama más bien negativo, también en relación con la política energética, cabe mencionar como excepción la Sentencia 136/2015, de 11 de junio (BOE, núm. 160, de 6 de julio de 2015), relativa al recurso de inconstitucionalidad interpuesto por la Junta de Extremadura en relación con diversos preceptos del Real Decreto-Ley 20/2012, de 13 de julio, de medidas para garantizar la estabilidad presupuestaria y de fomento de la competitividad. En este caso, el Tribunal Constitucional consideró que, efectivamente, no se daba el supuesto habilitante para la aprobación de un decreto-ley, introduciendo elementos de control en el uso de esta figura legislativa en una dirección contraria a la desarrollada en su jurisprudencia mayoritaria ${ }^{79}$. En cualquier caso, debe subrayarse que el pronunciamiento del Tribunal Constitucional no reposa, en absoluto, en consideraciones de carácter ambiental.

\section{Recentralización y regresión}

La progresiva confluencia de proceso recentralizador y políticas desarrollistas, que ha tenido su máxima expresión en materia energética, puede considerarse una evolución general que se evidencia en múltiples aspectos de la actividad normativa relacionada con la protección del medio ambiente. Una muestra de ello la constituye la STC 202/2013, de 5 de diciembre, que se pronuncia sobre el Acuerdo de 21 de marzo de 2007 del director territorial de la Consejería de Territorio y Vivienda de la Comunidad Valenciana en el que se ratificaba la orden de suspensión cautelar de las obras correspondientes al proyecto de una planta desaladora en el ámbito territorial del Parque Natural de las Lagunas de la Mata y Torrevieja ${ }^{80}$. Se trataba de un expediente sancionador por presunta

general -y que, de paso, favorecía el autoconsumo, que constituye, obviamente, una solución particularmente sostenible en este ámbito-.

${ }^{79}$ Así, en el FJ 6. ${ }^{\circ}$, el Tribunal considera, en este caso, que "si la justificación de la urgencia del conjunto de las medidas estructurales adoptadas en el sector eléctrico era la necesidad de combatir el déficit tarifario y garantizar la sostenibilidad del sistema en un contexto de reformas en diversos sectores económicos, es claro que esa justificación no es predicable de la medida que se examina, pues, en realidad, se modifica el régimen de una potestad de la que ya gozaba el Gobierno y que, de haberse aplicado efectivamente conforme al régimen que ahora se modifica por la norma de urgencia, hubiera conducido al mismo resultado que se afirma perseguir con las normas objeto del presente proceso".

${ }^{80}$ En relación con los conflictos que hacen visible el conflicto confluyente entre autonomía y centralización, por una parte, y entre protección del medio ambiente y estímulo de la actividad 
comisión de infracción administrativa de la Ley 11/1995, de 27 de diciembre, de espacios naturales protegidos de la Comunidad Valenciana, que comportaba la paralización cautelar de las obras. De acuerdo con la controvertida doctrina que atribuye la evaluación de impacto ambiental a la Administración responsable del proyecto, desplegada desde la STC 13/1998, de 22 de enero, el Tribunal, para salvaguardar la instalación de titularidad estatal, acababa impidiendo la actuación de la comunidad autónoma dirigida a proteger el medio ambiente ${ }^{81}$.

En definitiva, puede concluirse que el Tribunal Constitucional abona de manera clara una legislación desarrollista y se abstiene de tomar en consideración los aspectos ambientales de la política económica, particularmente en sectores sensibles como el energético. En este contexto, para cerrar este apartado, vale la pena mencionar la STC 233/2015, de 5 de noviembre, en relación con la discutida Ley 2/2013, de 29 de mayo, de protección y uso sostenible del litoral y de modificación de la Ley 22/1988, de 28 de julio, de Costas.

En esta decisión, el Tribunal Constitucional hace mención, por primera vez, al principio de no regresión en materia de medio ambiente, para excluir,

económica, por otra, que, en definitiva, vincula recentralización y regresión ambiental, también debe mencionarse la STC 157/2016, de 22 de septiembre, que resolvió el recurso de inconstitucionalidad promovido por el Presidente del Gobierno en relación con el artículo único del Decreto-Ley de la Generalitat de Catalunya 7/2014, de 23 de diciembre, por el que se deroga la letra b) del apartado 3 y el segundo párrafo del apartado 4 del artículo 9 del DecretoLey $1 / 2009$, de 22 de diciembre, de ordenación de los equipamientos comerciales. No voy a entrar en detalle en relación con este pronunciamiento del Tribunal. En todo caso, el proceso de recentralización es harto evidente, como pone de manifiesto la STC 165/2016, de 6 de octubre, en la que se puede observar un caso claro de ampliación de las competencias de las instituciones centrales del Estado en esta materia. El voto particular a esa sentencia, suscrito por la magistrada Adela Asua Batarrita, al que se adhiere el magistrado Juan Antonio Xiol Ríos, es bastante claro en relación con ello. En particular, señala que "el entendimiento de que la competencia estatal sobre las bases incluye con toda naturalidad la posibilidad de dictar actos de ejecución en cualquier materia" se ha generalizado en la jurisprudencia del Tribunal Constitucional, de modo que "ese particular entendimiento conduce a una importante alteración de las reglas de distribución competencial que derivan del bloque de constitucionalidad y produce, en consecuencia, un preocupante efecto corrosivo sobre las competencias de ejecución de las Comunidades Autónomas, cuyo ámbito competencial se va reduciendo progresivamente".

${ }^{81}$ Así, el Tribunal considera que la posibilidad de que una "Comunidad Autónoma pueda adoptar las medidas precisas para la protección del medio ambiente cuando considere que la actuación o proyecto estatal implica una ausencia de protección del aspecto medioambiental [...] no puede ser aceptada, pues supondría convertir la competencia sobre medio ambiente en una competencia prevalente sobre la competencia en materia de obras de interés general, desconociendo la doctrina de éste Tribunal que considera que es la Administración estatal la que ejerce sus propias competencias sustantivas sobre las obras, instalaciones o actividades proyectadas, aun cuando preceptivamente deba considerar su impacto medioambiental" (STC 202/2013, de 5 de diciembre, FJ 3. ${ }^{\circ}$ ). 
inmediatamente, cualquier pretensión de utilizarlo en el control del legislador a causa de "las dificultades intrínsecas a la propia extensión y abstracción de la noción de 'medio ambiente', y a la ausencia de parámetros previos que contribuyan a la identificación del contenido de ese instituto jurídico" ${ }^{82}$. En conclusión, de los diferentes casos analizados se percibe el vínculo, cada vez más evidente, entre programa recentralizador y desprotección ambiental, dentro de una interpretación del desarrollo sostenible que tiene mucho de lo primero y poco de lo segundo, excluyendo el uso del artículo $45 \mathrm{CE}$ como parámetro de constitucionalidad efectivo. Cabe preguntarse, en este punto, si existen alternativas.

\section{LA NECESIDAD DE DESPLEGAR UN CONTROL ROBUSTO DE CONSTITUCIONALIDAD ANTE LA REGRESIÓN NORMATIVA Y LA CAPTURA DEL LEGISLADOR}

Como hemos visto, nos encontramos ante la actitud más bien indiferente del Tribunal Constitucional en relación con la protección del medio ambiente, que parte de una interpretación ciertamente cómoda, pero al mismo tiempo muy poco garantista, de las implicaciones del artículo 53.3 CE en relación con las normas contenidas en el capítulo III del título I de la Constitución ${ }^{83}$. Creo que, por una parte, puede hacerse un uso más activo del artículo $45 \mathrm{CE}$ como parámetro de constitucionalidad y, por otra, creo también que puede adoptarse, en el contexto del sistema constitucional, una interpretación más crítica con la deriva desarrollista del legislador, maximizando la función tuitiva de la

\footnotetext{
${ }^{82}$ Vid. FJ 2.c. Ciertamente, el juez de la constitucionalidad reconoce que el legislador dispone de "un margen de configuración plenamente legítimo, amplio pero no ilimitado, pues está supeditado a los deberes que emanan del conjunto de la Constitución. Señaladamente, de la interpretación sistemática de los arts. 45 y $132 \mathrm{CE}$, que delimitan el contorno de la discrecionalidad del legislador, lógicamente más reducido cuando afecta al núcleo de los bienes demanializados ex art. 132.2 CE y más extenso cuando se trata de definir el dominio público de configuración legal o el régimen general de uso de los bienes de dominio público" (FJ 2.d). Sin embargo, es incapaz de llevar adelante la mínima argumentación para consagrar algún tipo de criterio en cuanto a los límites constitucionales del legislador en relación con el principio de no regresión.

${ }^{83}$ Entiendo que, efectivamente, el artículo 53.3 CE no implica la privación del carácter de parámetro de constitucionalidad del artículo $45 \mathrm{CE}$. En este sentido, me remito a JARIA I MANZANO, "Derechos y medio..." cit., p. 594 y ss.
} 
jurisdicción constitucional como elemento corrector de las posiciones mayoritarias $^{84}$.

En este sentido, me parece necesario remarcar que, aunque, ciertamente, de acuerdo con el artículo 53.3 CE, no pueden extraerse derechos de prestación directamente exigibles ante los tribunales a partir del artículo $45 \mathrm{CE}$, ello no excluye el control de constitucionalidad de las disposiciones con rango de ley sobre la base de esa disposición ${ }^{85}$. De acuerdo con ello, a mi juicio, debe avanzarse hacia un rol más activo del Tribunal Constitucional, en relación con las decisiones de afectación ambiental del legislador democrático, que permita revertir aquellas medidas de carácter regresivo que se han generalizado desde el estallido de la crisis, invirtiendo la jurisprudencia en exceso deferente a la que me he referido en el apartado anterior. En este punto, deben apuntarse dos argumentos fundamentales para reconstruir el control de constitucionalidad como elemento de garantía del marco constitucional de protección del medio ambiente ante la situación generada por la deriva desarrollista y liberalizadora del legislador democrático, que la crisis económica de 2007 ha intensificado.

En primer lugar, en el contexto de captura del legislador al que me he referido más arriba, la utilización de la legislación y la apelación a su legitimidad democrática ocultan, en muchas ocasiones, la decisión unilateral de un gobierno que controla su mayoría parlamentaria y que negocia con actores privados determinados proyectos o programas de manera más bien poco transparente. En este sentido, la legitimidad democrática de la decisión es puramente formal, sin que quepa excluir el control de constitucionalidad, justamente como garantía de una profundización democrática que debe

\footnotetext{
${ }^{84}$ Efectivamente, el fundamento del control de constitucionalidad es la protección de la minoría ante los excesos de la mayoría. Vid. MADISON, J., HAMILTON, A. y JAY, J., El Federalista, Institut d'Estudis Autonòmics, Barcelona, 2009 (edición catalana de Joan Solé Solé, con estudio introductorio de John Kincaid), p. 413 y ss. En este caso, ante las opciones desarrollistas del legislador democrático, que, por otro lado, aparece cautivo de los intereses empresariales, tal como se ha intentado mostrar más arriba, la jurisdicción constitucional debería actuar como un garante del medio ambiente, de acuerdo con el principio de no regresión al que el propio Tribunal Constitucional ha hecho referencia, como hemos visto.

${ }^{85}$ Vid., por todos, GARCÍA DE ENTERRÍA, E., La Constitución como norma y el Tribunal Constitucional, Civitas, Madrid, 1985 (3. ${ }^{a}$ edición), p. 69.
} 
permitir la fiscalización constitucional de decisiones cuyo escrutinio público ha sido más bien escaso ${ }^{86}$.

En segundo lugar, el control de constitucionalidad en materia de protección del medio ambiente sintoniza con el control del poder como fundamento del constitucionalismo. Debe notarse, en este caso, que, en definitiva, la puesta a disposición de los recursos naturales para los actores privados en determinadas condiciones implica el deterioro de la condición de los ciudadanos, que deben asumir las externalidades derivadas de la explotación subsiguiente, lo que, obviamente, acaba teniendo un contenido implícitamente expropiatorio $^{87}$.

Es cierto que la jurisprudencia constitucional ha apuntado hacia la imposibilidad de juzgar la adecuación de la ponderación realizada por el legislador, pero, por otro lado, puede considerarse que, cuando el sacrificio de bienes constitucionales en presencia es suficientemente grave, nos hallamos ante un supuesto de inconstitucionalidad de la norma, en la medida en que la ponderación deja de existir ${ }^{88}$. En este contexto, deben mencionarse algunas resoluciones (pocas) del Tribunal que, si bien no han utilizado el artículo $45 \mathrm{CE}$ como parámetro de constitucionalidad, han ejercido el control sobre ciertas decisiones legislativas con efectos de desprotección ambiental, lo que ofrecería el principio para un cambio de orientación en relación con la jurisprudencia citada más arriba.

\footnotetext{
${ }^{86}$ Así, si bien es cierto que la inconstitucionalidad por vulneración del principio democrático "sólo se producirá si el vicio o inobservancia denunciada [de los preceptos que regulan el procedimiento legislativo] afecta esencialmente al proceso de formación de la voluntad de los parlamentarios, de modo que sólo los vicios o defectos más graves provocan un déficit democrático en el proceso de elaboración de una norma que podría conducir a su declaración de inconstitucionalidad" (STC 136/2011, de 13 de septiembre, FJ $10 .^{\circ}$ ), ello no excluye que la legitimidad democrática de ciertas leyes sea de baja calidad, lo que debería permitir una mayor incidencia del Tribunal en la ponderación del legislador de los intereses en presencia, particularmente en relación con el sacrificio que se haga del bien jurídico medio ambiente. En definitiva, la realidad del proceso legislativo debería matizar el self-restraint.

${ }^{87}$ En relación con esto, el principio de quien contamina paga debería anclarse en la función social de la propiedad (art. 33.2 CE), así como en el sometimiento de toda la riqueza del país al interés general (art. 128.1 CE), más allá de los perjuicios que la externalización de los costes ambientales comporta desde el punto de vista de la distribución de las cargas públicas (art. 31.1 CE). Por otro lado, debería considerarse la relevancia constitucional del principio de precaución (art. 191.2 TFUE). En definitiva, de acuerdo con lo dicho más arriba, debería construirse un marco hermenéutico a partir de la presencia de diferentes normas materialmente constitucionales en presencia que permitiera hacer efectivo el control del legislador.
}

${ }^{88}$ Vid. STC 149/2011, de 28 de septiembre, FJ 3. ${ }^{\circ}$. 
Entre estas decisiones, destaca particularmente la STC 234/2012, de 13 de diciembre, que resolvió el recurso de inconstitucionalidad contra la disposición adicional octava de la Ley 1/2001, de 24 de abril, del Suelo de la Región de Murcia, que, mediante un aparente ajuste técnico, permitía la transformación en urbanizables de espacios que gozaban de especial protección, de modo destacado, del Parque Natural de Cabo Cope-Calnegre, que se subsumía así en la Actuación de Interés Regional (AIR) de "Marina de Cope", un futuro resort turístico ${ }^{89}$. En este caso, de acuerdo con el Tribunal Constitucional, la disposición controvertida "genera inseguridad jurídica sobre todos sus destinatarios, lo que supone, dado su ámbito material, generar inseguridad jurídica, en último término, sobre todos los ciudadanos en cuanto a las concretas partes del territorio autonómico acreedoras de protección ambiental, con las consecuencias de todo orden que ello conlleva, en particular en un ámbito en el que está en juego la realización de un bien constitucional como la preservación del medio ambiente ex art. 45 CE"90.

Si bien es cierto que la exclusión del artículo $45 \mathrm{CE}$ del núcleo de la ratio decidendi es decepcionante, en todo caso, la Sentencia abre el camino para un control de constitucionalidad robusto en relación con las decisiones del legislador que ponen en peligro el medio ambiente, lo que, ciertamente, es crucial dada la tendencia a la regresión en este ámbito a la que me he referido reiteradamente en este estudio ${ }^{91}$. En este sentido, cabe concebir un cambio de orientación a partir del que la justicia constitucional se enfrente a las ponderaciones radicalmente desequilibradas en relación con la protección del

\footnotetext{
${ }^{89}$ Sobre esta sentencia, vid. el comentario de Santiago M. Álvarez Carreño y Eduardo Salazar Ortuño en "Jurisprudencia ambiental en Murcia (Primer semestre 2013)", Revista Catalana de Dret Ambiental, vol. 4, núm. 1, 2013.

${ }^{90}$ Vid. FJ 8. ${ }^{\circ}$

${ }^{91}$ En cualquier caso, ha habido alguna otra sentencia prometedora, la STC 203/2013, de 5 de diciembre de 2013, que se pronunció en relación con la Ley de las Cortes de Castilla y León 6/2007, de 28 de marzo, de aprobación del Proyecto Regional "Ciudad del Medio Ambiente". Dados los déficits desde el punto de vista de la legitimidad democrática que tienen estas leyes orientadas a facilitar la realización de proyectos concretos, es una resolución de referencia en relación con el segundo de los elementos apuntados más arriba. En este caso, el Tribunal concluía que "la utilización de la ley no es una medida razonable ni proporcionada a la situación excepcional que ha justificado su aprobación" (FJ $8^{\circ}$ ), lo que conlleva la declaración de inconstitucionalidad. En este contexto, debe mencionarse de nuevo la STC 162/2014, de 7 de octubre, que anulaba la Ley 6/2010, de 28 de mayo, de declaración de Proyecto Regional del "Complejo de Ocio y Aventura Meseta-Ski". En este caso, sin embargo, la ratio decidendi tiene un carácter competencial.
} 
medio ambiente que puede operar un legislador de orientación francamente desarrollista $^{92}$. Las pistas que pueden recorrerse a partir de una idea de sistema constitucional más allá del aparato legitimador de la economía-mundo capitalista que constituye el entorno hermenéutico inmediato en el que se desarrolla el programa legislativo de regresión ambiental deben construirse a partir de una interpretación más compleja y matizada de las normas constitucionales en presencia. La idea de sistema constitucional como complejo de normas de origen diverso que confluyen en la decisión del Tribunal para fundamentar el control ejercido es un punto de partida metodológico para el desarrollo de una argumentación más densa y garantista en estos casos.

En este sentido, debe destacarse la posibilidad de acudir a normas consolidadas en el derecho internacional o en el derecho de la Unión Europea que contribuyan a reforzar el proceso hermenéutico a partir del cual, en el marco de una construcción compleja del derecho constitucional, pueda desarrollarse un control más robusto de los poderes públicos. En este sentido, sin ánimo de exhaustividad, pueden mencionarse dos principios que ofrecen enormes posibilidades en relación con ello. Por una parte, creo que es crucial el principio de precaución, que, desde su desarrollo en el derecho alemán en los años setenta del siglo pasado, ha venido a integrarse en el derecho de la Unión Europea, e incluso en el derecho internacional, como eje fundamental de la política ambiental ${ }^{93}$. Por otra, debe mencionarse el principio de responsabilidad, de largo alcance, que se manifiesta en principios más

\footnotetext{
${ }^{92}$ No cabe desconocer, sin embargo, el efecto perverso que pueda tener el artículo $135 \mathrm{CE}$. Se trata de una disposición constitucional que determina la actuación financiera de los poderes públicos de acuerdo con las exigencias de los mercados de capitales en los que deben colocar su deuda, con el objetivo de financiar el gasto público. Tal disposición es, por una parte, una clara adaptación a las exigencias supraconstitucionales, pero, por otra, elimina la autonomía de los poderes públicos estatales en relación con el gasto y, además, impacta en los equilibrios internos del ya frágil Estado social español. Su impacto potencial en la jurisprudencia constitucional en el contexto en el que me refiero está por ver. En cualquier caso, introducir el artículo $135.1 \mathrm{CE}$ en un balancing test con otros bienes jurídicos constitucionales parece un procedimiento apropiado para adecuar la estabilidad financiera a un contexto complejo que exige políticas públicas activas. Con ello, podría disminuirse la presión sobre el medio ambiente, concebido, en este momento, como un repositorio de recursos a explotar por inversores que, presuntamente, deben generar las condiciones de bienestar que los poderes públicos son incapaces de garantizar.

${ }^{93}$ Vid. HANSCHEL, D., "Progress and the Precautory Principle in Administrative Law - Country Report on Germany", RIEDEL, E. y WOLFRUM, R. (eds.), Recent Trends in German and European Constitutional Law, Springer, Berlín, Heidelberg, Nueva York, 2006, pp. 180-181. Debe señalarse que el principio viene explícitamente recogido en la Declaración de Río sobre el Medio Ambiente y el Desarrollo (1992), concretamente en su principio 15.
} 
concretos como el de quien contamina paga o el de responsabilidades comunes pero diferenciadas ${ }^{94}$.

\section{CONCLUSIÓN}

Partiendo de un marco constitucional complejo en el que se integran normas de vocación fundamental que forman parte del derecho internacional público, se constata la centralidad del desarrollo sostenible como argamasa en la definición de la orientación del derecho público económico. En el caso español, esta materia constitucional se integra en la Constitución formal a través de la interpretación. Debe señalarse, por otro lado, que el marco constitucional español define un Estado social frágil en el que la protección del medio ambiente obtiene un reconocimiento más bien marginal, al menos, en la interpretación mayoritaria que se ha hecho de la Constitución económica.

Este contexto, en el momento en el que estalla la crisis económica de 2007, define el trasfondo de la respuesta legislativa a la recesión. Ante la necesidad de garantizar la actividad de las grandes empresas para generar un crecimiento suficiente que, por una parte, cree empleo y, por otra, genere confianza en los mercados internacionales de capital, el legislador se lanza a un programa normativo altamente regresivo en materia ambiental. Esta panoplia de normas pretende reposar sobre la idea de desarrollo sostenible, dos de cuyos tres ejes -la protección del medio ambiente y la justicia social- han sido considerablemente debilitados en la evolución del derecho internacional reciente, como muestra la Declaración final de la Conferencia Río+20.

En este entorno más bien poco proclive a garantizar una protección del medio ambiente robusta ante la presión de los actores de la economía global sobre los recursos, el Tribunal Constitucional ha validado, con una jurisprudencia extremadamente deferente con el legislador, las regulaciones regresivas que

\footnotetext{
${ }^{94}$ El principio de quien contamina paga fue formulado por primera vez en 1972 por el Consejo de la Organización para la Cooperación y el Desarrollo Económicos (OCDE). En relación con este principio, vid., entre otros, JORDANO FRAGA, J., La protección del derecho a un medio ambiente adecuado, J. M. Bosch, Barcelona, 1995, p. 137 y ss.; y ROTA, L., Los principios... cit., p. 64 y ss. En relación con el principio de responsabilidades comunes pero diferenciadas, vid., particularmente, ELIZALDE CARRANZA, M. Á., "Desarrollo y cambio climático", Revista Catalana de Dret Ambiental, vol. 1, núm. 1, 2010, pp. 11-12.
} 
se han ido aprobando desde el inicio de la crisis, al mismo tiempo que ha expulsado del sistema normativas de carácter tuitivo, como ha sucedido en el caso de la fractura hidráulica o de las energías renovables. De este modo, el juez de la constitucionalidad ha colaborado activamente en un proceso en el que se ha aunado la recentralización con la regresión ambiental.

Ante tal jurisprudencia constitucional, de una orientación claramente mayoritarista y con una aproximación superficial y banal a la crisis ecológica que subyace a la crisis económica presente, se ha planteado la necesidad de explorar vías alternativas en la selección e interpretación de las normas constitucionales en presencia que permitan construir un control efectivo del legislador ante la desprotección ambiental generada en los últimos años. En este sentido, partiendo de la eficacia del artículo $45 \mathrm{CE}$ en el control de constitucionalidad, se propone avanzar hacia marcos hermenéuticos que permitan la evaluación de las ponderaciones efectuadas por el legislador en un contexto de sostenibilidad suficientemente sólido.

\section{BIBLIOGRAFÍA}

AGUILERA VAQUÉS, Mar, El desarrollo sostenible y la Constitución Española, Atelier, Barcelona, 2000.

ALBERTÍ ROVIRA, Enoch, Autonomía política y unidad económica, Civitas, Madrid, 1995.

ALDER, John y WILKINSON, David, Environmental Law \& Ethics, Macmillan, Londres, 1999.

ALTVATER, Elmar, El precio del Bienestar, Alfons el Magnànim, Valencia, 1994 (versión castellana de Manuel Ardid Lorés).

ÁlVAREZ CARREÑO, Santiago M. y SALAZAR ORTUÑO, Eduardo, “Jurisprudencia ambiental en Murcia (Primer semestre 2013)", Revista Catalana de Dret Ambiental, vol. 4, núm. 1, 2013.

APARICIO PÉREZ, Miguel Ángel, Introducción al sistema político y constitucional español, Ariel, Barcelona, 1991 (5. edición). 
- "El Estado social en la jurisprudencia del Tribunal Constitucional", CÁMARA VILLAR, Gregorio y CANO BUESO, Juan (eds. y coords.), Estudios sobre el Estado Social. Estado Social y Comunidad Autónoma de Andalucía, Tecnos, Madrid, 1993, pp. 47-71.

ASENSI SABATER, José, Constitucionalismo y Derecho constitucional, Tirant lo Blanch, Valencia, 1996.

BALAGUER CALLEJÓN, Francisco, "Derechos fundamentales y Constitución normativa", VV. AA., Introducción a los derechos fundamentales (I), Ministerio de Justicia, Madrid, 1988, pp. 207-225.

BARBANCHO TOVILLAS, Francisco José, Evolución del pensamiento económico y el Derecho civil: ensayo para su enseñanza, Signo, Esplugues de Llobregat, 1991.

BASSOLS COMA, Martín, Constitución y sistema económico, Tecnos, Madrid, 1985.

BAUDRILLARD, Jean, La sociedad de consumo. Sus mitos, sus estructuras, Siglo XXI, Madrid, 2009 (traducción de Alicia Bixio con estudio preliminar de Luis Enrique Alonso).

BOSSELMANN, Klaus, The Principle of Sustainability. Transforming Law and Governance, Ashgate, Farnham, Burlington, 2008,

BUCK-MORSS, Susan, Origen de la dialéctica negativa. Theodor W. Adorno, Walter Benjamin y el Instituto de Frankfurt, Siglo XXI, México, Madrid, Buenos Aires, Bogotá, 1981 (versión castellana de Nora Rabotnikof Maskivker).

- "Envisioning Capital: Political Economy On Display", COOKE, Lynne y WOLLEN, Peter (eds.), Visual Display. Culture Beyond Appereances, Bay Press, Seattle, 1995, pp. 111-141.

CABRERA, Mercedes, "Los Pactos de La Moncloa: acuerdos políticos frente a la crisis", Historia y Política, núm. 26, 2011, pp. 81-110.

CANOSA USERA, Raúl, Constitución y medio ambiente, Dykinson, Madrid, 2000. 
CAPEL, Horacio, Capitalismo y morfología urbana en España, Amelia Romero, Barcelona, 1983.

CARDESA-SALZMANN, Antonio, COCCIOLO, Endrius y JARIA I MANZANO, Jordi, "Whither Sustainable Development? The Global Economic System's Contribution to Sustain Ecologically Unequal Exchange", Proyecto "Del desarrollo sostenible a la justicia ambiental: Hacia una matriz conceptual para la gobernanza global" (DER2013-44009-P), informe núm. 7, 2016.

CASTILLO, Mayari y DURAND, Anahí, "Movimiento cocalero, política y representación: los casos boliviano y peruano", GARCíA, Fernando (comp.), Identidades, etnicidad y racismo en América Latina, FLACSO, Quito, 2008, pp. 47-72.

CLARKSON, Stephen y WOOD, Stepan, A Perilous Imbalance. The Globalization of Canadian Law and Governance, UBC Press, Vancouver, Toronto, 2009.

COMISIÓN MUNDIAL DEL MEDIO AMBIENTE Y DEL DESARROLLO, Nuestro futuro común, Alianza Editorial, Madrid, 1988.

CROOK, Stephen, PATULSKI, Jan y WATERS, Malcolm, Postmodernization. Change in Advanced Society, Sage, Londres, Thousand Oaks, Nueva Delhi, 1992.

CRUTZEN, Paul J., "Geology of mankind”, Nature, vol. 415, 2002, p. 23.

DAL BÓ, Ernesto, "Regulatory Capture: A Review", Oxford Review of Economic Policy, vol. 22, núm. 2, 2006, pp. 203-225.

DE CABO MARTÍN, Carlos, Pensamiento crítico, constitucionalismo crítico, Trotta, Madrid, 2014.

DE LA CUADRA SALCEDO, Tomás, "La Constitución económica de España. Comentario introductorio al Título VII", ALZAGA VILLAAMIL, Óscar (dir.), Comentarios a la Constitución española de 1978 (X), Edersa, Madrid, 1998, pp. 15-44.

DOBSON, Andrew, Justice and the Environment. Conceptions of Environmental Sustainability and Dimensions of Social Justice, Oxford University Press, Oxford, 1998. 
ECHEVERRÍA, Julio, "Complejización del campo político en la construcción democrática en el Ecuador", BURBANO DE LARA, Felipe (coord.), Transiciones y rupturas. El Ecuador en la segunda mitad del Siglo XX, FLACSO, Sede Ecuador, Quito, 2010, pp. 75-114.

“Editorial: Involución ambiental y respuesta constitucional”, Revista Catalana de Dret Ambiental, vol. 4, núm. 1, 2013.

ELIZALDE CARRANZA, Miguel Ángel, "Desarrollo y cambio climático", Revista Catalana de Dret Ambiental, vol. 1, núm. 1, 2010.

FERNÁNDEZ RODRÍGUEZ, José Julio, La inconstitucionalidad por omisión. Teoría general. Derecho comparado. El caso español, Civitas, Madrid, 1998.

FISCHER-KOWALSKI, Marina, "Society's Metabolism: The Intellectual History of Materials Flow Analysis, Part I, 1860-1970", Journal of Industrial Ecology, vol. 2, núm. 1, 1998, pp. 61-78.

FISCHER-KOWALSKI, Marina y HÜTTLER, Walter, "Society's Metabolism: The Intellectual History of Materials Flow Analysis, Part II, 1980-1998”, Journal of Industrial Ecology, vol. 2, núm. 4, 1998, pp. 107-136.

FONTANA, Josep, Por el bien del imperio. Una historia del mundo desde 1945, Pasado \& Presente, Barcelona, 2011.

GARCÍA DE ENTERRÍA, Eduardo, La Constitución como norma y el Tribunal Constitucional, Civitas, Madrid, 1985 (3. ${ }^{a}$ edición).

GARCÍA HERRERA, Miguel Ángel y MAESTRO BUELGA, Gonzalo, "Regulación constitucional y posibilidad del Estado social", Revista Vasca de Administración Pública, núm. 22, 1988, pp. 87-115

GARCÍA-PELAYO, Manuel, "El 'status' del Tribunal Constitucional”, Revista Española de Derecho Constitucional, núm. 1, 1981, pp. 18-19.

GETHMANN, Carl Friedrich, "Individuelle Freiheit und Umweltschutz aus philosophischer Sicht", KLOEPFER, Michael (ed.), Umweltstaat als Zukunft, Economica, Bonn, 1994, pp. 42-54.

HANSCHEL, Dick, "Progress and the Precautory Principle in Administrative Law - Country Report on Germany", RIEDEL, Eibe y WOLFRUM, Rüdiger (eds.), 
Recent Trends in German and European Constitutional Law, Springer, Berlín, Heidelberg, Nueva York, 2006, pp. 179-209.

HELD, David, MCGREW, Anthony, GOLDBLATT, David y PERRATON, Jonathan, Global Transformations. Politics Economics and Culture, Polity, Cambridge, 1999.

HERNÁNDEZ GIL, Antonio, "La propiedad privada y su función social”, Poder Judicial, núm. 14 (segunda época), 1989, pp. 9-22.

HESSE, Konrad, "Concepto y cualidad de la Constitución", Escritos de Derecho Constitucional, Centro de Estudios Constitucionales, Madrid, 1992 (edición castellana de Pedro Cruz Villalón), pp. 1-29.

JARIA I MANZANO, Jordi, El sistema constitucional de protecció del medi ambient, Institut d'Estudis Autonòmics, Barcelona, 2005, p. 35 y ss.

- "Problemas competenciales fundamentales en materia de protección del medio ambiente", Revista Vasca de Administración Pública, núm. 73 (I), 2005, pp. 117-134.

- "Jurisprudencia constitucional en materia de protección del medio ambiente (Segundo semestre 2014)", Revista Catalana de Dret Ambiental, vol. 5, núm. 2, 2014.

- "Derechos y medio ambiente", NOGUERA FERNÁNDEZ, Albert y GUAMÁN HERNÁNDEZ, Adoración, Lecciones sobre Estado social y derechos sociales, Tirant lo Blanch, Valencia, 2014, pp. 577-615.

- "El constitucionalismo de la escasez (derechos, justicia y sostenibilidad)", Revista Aranzadi de Derecho Ambiental, núm. 30, 2015, pp. 295-349.

- "La identificación del Derecho aplicable en un contexto normativo complejo", VV. AA., Diálogos sobre la justicia y los jueces, Centre d'Estudis Jurídics i Formació Especialitzada, Barcelona, 2015, pp. 89-117.

- "Jurisprudencia constitucional en materia de protección del medio ambiente (primer semestre 2016)", Revista Catalana de Dret Ambiental, vol. 7, núm. 1, 2016. 
- "El Derecho, el Antropoceno y la justicia", Revista Catalana de Dret Ambiental, vol. 7, núm. 2, 2016.

- $\quad$ "La externalización de costes ambientales en el acceso a los recursos naturales: marco institucional y distribución inequitativa", Proyecto "Del desarrollo sostenible a la justicia ambiental: Hacia una matriz conceptual para la gobernanza global" (DER2013-44009-P), informe núm. 4, 2016.

JONAS, Hans, El principio de responsabilidad. Ensayo de una ética para la civilización tecnológica, Herder, Barcelona, 1995 (versión castellana de José María Fernández Retenaga).

JORDANO FRAGA, Jesús, La protección del derecho a un medio ambiente adecuado, J. M. Bosch, Barcelona, 1995.

JOSITSCH, Daniel, "Das Konzept der nachhaltigen Entwicklung (Sustainable Development) im Völkerrecht und seine innerstaatliche Umweltsetzung", Umweltrecht in der Praxis / Le Droit de l'environnement dans la pratique, 1997, pp. 93-121.

KLABBERS, Jan, PETERS, Anne y ULFSTEIN, Geir, The Constitutionalization of International Law, Oxford University Press, Oxford, 2009.

KOTZÉ, Louis J., “Arguing Global Environmental Constitutionalism", Transnational Environmental Law, núm. 1, 2012, pp. 199-233.

LAPORTA, Francisco J., "Globalización e imperio de la ley. Algunas dudas westfalianas", CARBONELL, Miguel y VÁZQUEZ, Rodolfo (eds.), Globalización y Derecho, Ministerio de Justicia y Derechos Humanos, Quito, 2009, pp. 213243.

LOPERENA ROTA, Demetrio, Los principios del Derecho ambiental, Civitas, Madrid, 1998.

LÓPEZ GARRIDO, Diego, "Apuntes para un estudio sobre la Constitución económica", Revista del Centro de Estudios Constitucionales, núm. 15, 1993, pp. 79-96.

LÓPEZ Y LÓPEZ, Ángel M., La disciplina constitucional de la propiedad privada, Tecnos, Madrid, 1988. 
LUCAS VERDÚ, Pablo, "Estado de Derecho y justicia constitucional. Aspectos históricos, ideológicos y normativo-institucionales de su interrelación”, Revista de Estudios Políticos, núm. 33 (nueva época), 1983, pp. 7-48.

MALANCZUK, Peter, "Die Konferenz der Vereinten Nationen über Umwelt und Entwicklung (UNCED) und das internationale Umweltrecht”, BEYERLIN, Ulrich, BOHTE, Michael, HOFMANN, Rainer y PETERSMANN, Ernst-Ulrich (eds.), Recht zwischen Umbruch und Bewahrung. Festschrift für Rudolf Bernhardt, Springer, Berlín, Heidelberg, Nueva York, 1995, pp. 985-1002.

MARX, Karl, El Capital (Libro I - Tomo I), Akal, Tres Cantos, 2000 (2. ${ }^{a}$ edición castellana a cargo de Vicente Romano García).

MAZOWER, Mark, Der dunkle Kontinent. Europa im 20. Jahrhundert, Fischer, Frankfurt am Main, 2000 (versión alemana de Hans-Joachim Maass).

MELUCCI, Alberto, Vivencia y convivencia. Teoría social para una era de la información, Trotta, Madrid, 2001 (edición castellana de Jesús Casquette).

MÜLLER-BROMLEY, Nicolai, Staatszielbestimmung Umweltschutz im Grundgesetz? Rechtsfragen der Staatszielbestimmung als Regelungsform der Staatsaufgabe Umweltschutz, Eric Schmidt, Berlín, 1990.

MURSWIEK, Dietrich, Umweltschutz als Staatszweck, Economica, Bonn, 1995. NOGUEIRA LÓPEZ, Alba, BORRÀS PENTINAT, Susana, GILES CARNERO, Rosa y JARIA I MANZANO, Jordi, "Marco general. El medio ambiente en los tiempos de globalización neoliberal", SANZ LARRUGA, Francisco Javier, PERNAS GARCÍA, J. José (dirs.) y SÁNCHEZ, Jennifer (coord.), Derecho ambiental para una economía verde. Informe ECOVER, Thomson ReutersAranzadi, Cizur Menor, 2016, pp. 21-48.

NOGUERA FERNÁNDEZ, Albert, La igualdad ante el fin del Estado Social. Propuestas constitucionales para construir una nueva igualdad, Sequitur, Madrid, 2014.

PÉREZ ROYO, Javier, "La doctrina del Tribunal Constitucional sobre el Estado Social”, Revista Española de Derecho Constitucional, núm. 10, 1984, pp. 157181. 
PERNICE, Ingolf y KANITZ, Ralf, Fundamental Rights and Multilevel Constitutionalism in Europe, Walter Hallstein-Institut Paper, marzo 2004.

POLAKIEWICZ, Jörg, "El proceso histórico de implantación de los derechos fundamentales en Alemania", Revista de Estudios Políticos, núm. 81 (nueva época), 1993, pp. 23-45.

POYAL COSTA, Ana, Normas constitucionales y realidad. Análisis de su intervención transformadora, UNED, Madrid, 1995.

ROBERTS, J. Timmons y PARKS, Bradley C., "Ecologically Unequal Exchange, Ecological Debt, and Climate Justice. The History and Implications of Three Related Ideas for a New Social Movement", International Journal of Comparative Sociology, vol. 50, núms. 3-4, 2009, p. 389.

RUIZ ROBLEDO, Agustín, "Un componente especial de la Constitución económica: La protección del medio ambiente", Revista Andaluza de Administración Pública, núm. 14, 1993, pp. 27-53.

SANTAMARÍA ARINAS, René Javier, "Las claves jurídicas del debate sobre el fracking", Revista Catalana de Dret Ambiental, vol. 5, núm. 1, 2014.

SCHLÖGEL, Karl, Terror y utopía. Moscú en 1937, Acantilado, Barcelona, 2014 (traducción al castellano de José Aníbal Campos).

SIERRA PÉREZ, Pilar, Obligaciones "propter rem" hoy: los gastos comunes en la propiedad horizontal, Tirant lo Blanch, Valencia, 2002.

STIGLITZ, Joseph, The Price of Inequality, Norton, Nueva York, Londres, 2013.

TAYLOR, Peter J. y FLINT, Colin, Geografía política. Economía-mundo, estado-nación y localidad, Trama, Madrid, 2002 (2. ${ }^{a}$ edición castellana a cargo de Adela Despujol Ruiz-Jiménez y Heriberto Cairo Carou).

THÜRER, Daniel, "Recht der internationalen Gemeinschaft und Wandel der Staatlichkeit”, THÜRER, Daniel, AUBERT, Jean-François y MÜLLER, Jörg Paul (eds.), Verfassungsrecht der Schweiz / Droit constitutionnel suisse, Schulthess, Zúrich, 2001, pp. 37-61.

TOLEDO, Víctor M., "El metabolismo social: una nueva teoría socieconómica", Relaciones, núm. 136, 2013, pp. 41-71. 
VERNET I LLOBET, Jaume, "La apertura del sistema autonómico", Anuario de Derecho Constitucional y Parlamentario, núm. 14, 2002, pp. 127-169.

VON BOGDANDY, Armin, "Comparative Constitutional Law: A Contested Domain. A. Comparative Constitutional Law: A Continental Perspective", ROSENFELD, Michel y SAJÓ, András, The Oxford Handbook of Comparative Constitutional Law, Oxford University Press, Oxford, 2012, pp. 25-37.

WALLERSTEIN, Immanuel, El moderno sistema mundial. I. La agricultura capitalista y los orígenes de la economía-mundo en el siglo XVI, Siglo XXI, Madrid, 2010 (2. ${ }^{a}$ edición castellana a cargo de Antonio Resines).

WEISZ, Helga, "Combining Social Metabolism and Input-Output Analysis to Account for Ecologically Unequal Trade", HORNBORG, Alf, MCNEILL, John Robert y MARTÍNEZ-ALIER, Joan (eds.), Rethinking Environmental History: World-System History and Global Environmental Change, AltaMira Press, Lanham, pp. 289-306.

WESTAWAY, Jennifer, "Globalization, Transnational Corporations and Human Rights - A New Paradigm”, International Law Research, vol. 1, núm. 1, 2012, pp. 63-72.

WILDHABER, Luzius, "Soziale Grundrechte", SALADIN, Peter y WILDHABER, Luzius (eds.), Der Staat als Ausgabe. Gedenkschrift für Max Imboden, Helbing \& Lichtenhahn, Basilea-Stuttgart, 1972, pp. 371-391.

ZAGREBELSKY, Gustavo, El derecho dúctil. Ley, derechos, justicia, Trotta, Madrid, 1995 (versión castellana a partir del original italiano a cargo de Marina Gascón).

ZUMBASEN, Peer, "Carving our typologies and Accounting for differences across Systems: towards a methodology of transnational constitutionalism", ROSENFELD, Michel y SAJÓ, András, The Oxford Handbook of Comparative Constitutional Law, Oxford University Press, Oxford, 2012, pp. 75-97. 